BNL - 61520

Informal Report

\title{
Multiple-Linac Approach for Tritium Production and Other Applications
}

\author{
Alessandro G. Ruggiero
}

January 10, 1995

\section{Department of Advanced Technology}

\author{
Brookhaven National Laboratory \\ Associated Universities, Inc. \\ Upton, Long Island, New York 11973 \\ Under Contract No. DE-AC02-76CH00016 with the \\ UNITED STATES DEPARTMENT OF ENERGY
}




\section{DISCLAIMER}

This report was prepared as an account of work sponsored by the United States Government. Neither the United States nor the United States Department of Energy, nor any of its employees, nor any of their contractors, subcontractors, or their employees, makes any warranty, express or implied, or assumes any legal liability or responsibility for the accuracy, completeness, or usefulness of any information, apparatus, product or process disclosed, or represents that its use would not infringe privately owned rights. 


\section{DISCLAIMER}

Portions of this document may be illegible in electronic image products. Images are produced from the best available original document. 


\title{
Multiple-Linac Approach for Tritium Production and Other Applications*
}

\author{
Alessandro G. Ruggiero \\ Brookhaven National Laboratory \\ January 10, 1995
}

\begin{abstract}
This report describes an approach to tritium production based on the use of multiple proton linear accelerators. Features of a single APT ${ }^{\dagger}$ Linac as proposed by the Los Alamos National Laboratory are presented and discussed. An alternative approach to the attainment of the same total proton beam power of $200 \mathrm{MW}$ with several lower-performance superconducting Linacs is proposed and discussed. Although each of these accelerators are considerable extrapolations of present technology, the latter can nevertheless be built at less technical risk when compared to the single high-current APT Linac, particularly concerning the design and the performance of the lowenergy front-end. The use of superconducting cavities is also proposed as a way of optimizing the accelerating gradient, the overall length, and the operational costs. The superconducting technology has already been successfully demonstrated in a number of large-size projects and should be seriously considered for the acceleration of intense low-energy beams of protons. Finally, each linear accelerator would represent an ideal source of very intense beams of protons for a variety of applications, such as: weapons and waste actinide transmutation processes, isotopes for medical application, spallation neutron sources, and the generation of intense beams of neutrinos and muons for nuclear and high-energy physics research. The research community at large has obviously an interest in providing expertise for, and in having access to, the demonstration, the construction, the operation, and the exploitation of these top-performance accelerators
\end{abstract}

\section{The APT Linac}

The Los Alamos reference design of the APT Linac for tritium production ${ }^{1}$ is based on the use of a single accelerator device where the 200-MW design goal of proton beam power is generated by selecting an average beam current of $200 \mathrm{~mA}$ and a final energy of $1 \mathrm{GeV}$. The project is schematically shown in Figure 1 with proposed phases of construction ${ }^{2}$. The design has been optimized, to some low-order approximation, by assuming a normal-conducting rf-cavity accelerating system. Its feasibility has been evaluated and reviewed on several occasions as correct ${ }^{3}$. It is in particular a very clear demonstration that the accelerator technology can compete as a viable alternative to nuclear reactors for applications where the accelerator power requirements are not

†. Accelerator-based Production of Tritium

* Work performed under the auspices of the US Department of Energy 
prohibitively large. Nevertheless, the APT Linac has not yet been optimized to a higher degree, and other accelerator scenarios so far have not been considered. With the present design, the APT Linac is perceived to contain a considerable dose of technological risk. Some of the most relevant design features are described below with technical considerations.

The Linac is essentially made of two parts: the front-end, which is the most crucial for the overall beam performance, and the high-energy section, which determines the length of the accelerator, and dominates the capital and operation cost.

An average of proton beam current of $200 \mathrm{~mA}$ cannot be delivered by a single ion source. Thus, the reference design calls for two ion sources, each producing around $110 \mathrm{~mA}$. Even this current level is too large. In a recent workshop held at Lawrence Berkeley Laboratory, positive-ion sources were reviewed by experts from several institutions in USA, Europe, and Japan. A summary table ${ }^{4}$ was agreed upon which is reproduced herein as Table 1 . A source-current value of 60 $\mathrm{mA}$ has been demonstrated satisfactorily with long-term stability and reproducibility. It is obvious that a lower average beam current, at the source, is more desirable as a starting design parameter, especially to guarantee reliable and reproducible operation over long periods of time.

In order to reach the design beam current of $200 \mathrm{~mA}$, the APT Linac requires the duplication of the front-end with certain technical consequences caused by the combination of two beams in the following high-energy section of the accelerator. The use of an rf funnel (which works as the inverse of an if separator) dictates the choice of $20 \mathrm{MeV}$ as the energy where the two beams are merged, and thus produces the need of an intermediate low-energy Drift-Tube Linac separated by a Bridge-Coupled Drift-Tube Linac. Moreover, the same funneling principle requires the designer to operate the following Coupled-Cavity Linac at the frequency of $700 \mathrm{MHz}$, twice the frequency of the front-end section.

The larger frequency of the normal-conducting CCL, and the need for controlling the value of the cavity shunt impedance to reduce power dissipation, allow only a modest cavity aperture of 50 $\mathrm{mm}$. Moreover, there is the concern that the large beam intensity will generate a considerable beam halo with the possibility of activation of the accelerator over long periods of time, which is difficult, if not impossible, to evaluate and to control in practice. It seems preferable to double the internal cavity dimension by choosing a superconducting structure operating at a lower accelerating frequency and at the same time lowering the beam current by a large factor. The lower beam current can then be achieved with a single front-end module with a greatly simplified design.

Some staging of the APT Linac, as recently proposed by the Los Alamos team, is certainly possible. But the proposal requires that, at all times, all parts of the system work simultaneously and correctly to deliver the design goal of beam power. The failure of the project, that can be tested only a long period after completion, will not provide alternatives or easy modification to other, more flexible, schemes. Furthermore, the proposed staging ${ }^{2}$ does not really remove the major concern of the considerable technical risk, especially of the front-end. The proposed staging calls for an initial reduced energy of $500 \mathrm{MeV}$ and a single front-end module. Subsequently, the energy is raised to $1000 \mathrm{MeV}$, and, finally, a second parallel front-end is added with the funnel system in place. Thus, the proposed staging does not approach the demonstration of technical performance in steps, but it merely addresses only phasing of the cost expenditure. Furthermore, the few stages 
of construction do not take into account tritium production, with the result of a poor production efficiency especially during the early period.

Finally, the present APT design calls for two targets for intermediate neutron spallation leading to tritium production. The design of the targets is grossly affected by unknowns due to the large amount of beam power involved and to the large size, with considerable extrapolations for the estimate of cooling, safety, and radiation hazard. Smaller-size targets, in a multiple arrangement, would be easier to design and to operate.

\section{Comparison with Existing Facilities}

The reference APT Linac design calls for a nominal 200-MW beam power. This is two orders of magnitude above demonstrated technology. Accelerator technology has the capability to progress fast, but absorbing too large a jump in performance is at certain risk. Considering the nature of the application of the project, production and stockpiling of tritium, it is crucial that the accelerator project works immediately according to specifications, reliably and practically at full-time schedule. No intense research and development program should be required to demonstrate crucial beam and accelerator performance. Yet the project, as it has been proposed, has built in a considerable technical risk which may be reduced by adopting a different scenario based on multiple lower-performance superconducting linacs.

Table 2 is a list ${ }^{5}$ of the major intense proton sources up to few GeV. Those shown first are operating facilities among which notably is the 800-MeV LAMPF at Los Alamos, which is capable of delivering almost $1 \mathrm{MW}$ of beam power (when the LAMPF is used as the injector to the Proton Storage Ring as a pulsed spallation neutron source, the available power is less than a $100 \mathrm{~kW}$, owing to intensity limitations encountered during filling of the PSR). The most powerful pulsed spallation neutron source is ISIS at the Rutherford Appleton Laboratory in the UK, with an average beam power of $160 \mathrm{~kW}$, whereas the AGS Booster, with acceleration to $1.5 \mathrm{GeV}$ and 7.5 beam pulses per second, can provide only $30 \mathrm{~kW}$. There are thus two orders of magnitude between the demonstrated performance of operating facilities and the requirements of the APT Linac. In between, there are several projects in the few-MW range which are at the moment in the proposal stage and under investigation (AUSTRON, ANL, NCNR, BNL, ESS, ANS, ETA,...). The next project under construction ${ }^{6}$ is SINQ (Zurich, Switzerland) with a design beam power of $0.9 \mathrm{MW}$. Accelerator technology has the capability of progressing at fast rate, but it is doubtful that with the APT project we can absorb such a large jump as two orders of magnitude in a single step. One order of magnitude at a time over about a decade is more realistic, as it has been historically demonstrated.

Table 3 gives the list of operating proton linacs in USA. Table 4 is a summary of proton linacs that have been recently proposed in USA. It is noted that, with the exception of the APT Linac, none operates in continuous mode of operation, and that all make use of normal-conducting cavities.

The construction period proposed for the APT Linac is 12 years. Considering the size and the considerable jump in performance, one should expect in addition a long commissioning period before the full design parameters will be reached and satisfactorily demonstrated. Accelerator projects are known for long turn-on periods following the end of construction before they reach full capa- 
bility. The length of the construction and commissioning periods is proportional to the complexity and the size of the project. Thus, tritium may be produced only after several years of preoperational testing, unless an alternative scenario is developed with the goal of reducing the turn-on and delivery period.

One of the most important requirement is the availability of the tritium plant for a large fraction of yearly time (75\%). This, in turn, requires that both the accelerator and the targets have also large rates of yearly availability, probably in excess of $90 \%$. Few particle accelerators have reached these high rates averaged over many years, and eventually only after long periods of commissioning and operation. These rates, though, may be achieved with higher confidence by taking a design with modularity and multiplicity in the performance built in from the start.

\section{Multiple-Accelerator Approach}

The following describes an alternative scenario with the same goal of $\mathrm{P}_{\text {total }}=200 \mathrm{MW}$ of beam power, but divided into a number of smaller accelerators of reduced requirements that can be built sooner, more conservatively, and more reliably. The major thrust is a reduction of the overall technical risk. The proposed scenario assumes that $\mathrm{N}_{\mathrm{A}}$ accelerators are built each of beam power $\mathrm{P}_{0}$, so that

$N_{A} P_{0}=P_{\text {total }}=200 \mathrm{MW}$

For instance, a reasonable solution could be $\mathrm{N}_{\mathrm{A}}=4$ accelerators built, simultaneously or in sequence, on the same site or at several sites, as described below, each delivering a beam power of $\mathrm{P}_{0}=50 \mathrm{MW}$. This power figure is an order of magnitude larger than what has been considered in present pulsed spallation neutron studies around the world. It would yield an amount of available neutrons at even larger rates than those of the Advanced Neutron Source ${ }^{7}$ of Oak Ridge, which is based on nuclear-reactor technology. Each of these accelerators of 50-MW beam power could also constitute facilities for experimenting on energy production, nuclear transmutation for weapons and actinides waste management, medical and other isotope production, and for a variety of other applications in nuclear and neutron physics, like the generation of very intense secondary beams of neutrinos and muon mesons. According to the application, several combinations of beam parameters are possible; for instance, energy can been traded with current for the same beam power.

\section{Linear versus Circular Accelerators}

As for the 1-5 MW pulsed neutron sources at the 50-MW level of beam power, it is legitimate to question which is the most advantageous accelerator technology, among Linacs, Synchrotrons, Accumulator Rings, Cyclotrons, and Fixed-Field-Alternating-Gradient accelerators. It is difficult to conceive of an application of such large rf power in Cyclotrons or FFAG machines, and thus they should be disregarded from start, despite the fact the SINQ project is based on a Cyclotron but likely limited to only $1 \mathrm{MW}$. Synchrotrons ${ }^{8}$ and Accumulator Rings ${ }^{9}$ are needed if the neutron beam is to be pulsed in brief bursts of short length (microseconds) at the rate of 10-60 Hz. Moreover, there is always a need of a linear accelerator as the injector which in the case of Accumulator Rings has also to provide the full beam energy and power. The advantage of the Synchrotrons 
exists only if the beam energy is large, ten $\mathrm{GeV}$ or more, in which case conventional normal-conducting Linacs may be too expensive and less feasible. Depending on the type and nature of the application, the facility ultimately is made of a combination of linear and circular accelerators, either to boost the beam to higher energies or to provide the required time duration of the beam pulses. For the application of tritium production, if the total proton energy does not exceed a few $\mathrm{GeV}$, as will be assumed in the following, a linear accelerator operating in continuous-wave mode represents the most feasible and cheapest solution, which also demands less operating power. In other applications, the linear accelerator may be the injector to a subsequent device.

\section{General Design Considerations}

Each of the smaller linear accelerators requires less average beam intensity; for instance, $50 \mathrm{~mA}$ at the final energy of $1 \mathrm{GeV}$, or $25 \mathrm{~mA}$ at $1.8 \mathrm{GeV}$ and $\mathrm{P}_{0}=45 \mathrm{MW}$, which is closer to the present capabilities of available ion sources. Both the concern of the latent activation due to the formation of beam halo, and the constraints on the design of the front end would be significantly reduced. In particular, there is no need for beam funneling and a single-value frequency can be adopted throughout the whole accelerating device, for instance $350 \mathrm{MHz}$, which allows a larger cavity internal diameter of $100 \mathrm{~mm}$, for the containment of the beam.

The use of superconducting cavities is also proposed. They indeed do represent by now a mature technology with several advantages. With a normal-conducting system, special attention need be given to the power dissipated in the walls of the cavities owing to the large wall resistivity. To reduce this power, which is dissipated also without beam acceleration, the design of the APT Linac calls for a low average accelerating gradient of about $1 \mathrm{MV} / \mathrm{m}$ and a small cavity opening of $50 \mathrm{~mm}$. With superconducting cavities, it is possible to remove entirely the power dissipated in the walls of the cavity structure by raising considerably the shunt impedance, so that one has the freedom to opt for larger accelerating gradients of several $\mathrm{MV} / \mathrm{m}$ which will shorten the length of the accelerating structure. Moreover, a considerable savings on the operation cost of the facility over a long period of time can be expected.

As for the application to the production of tritium with multiple linacs with superconducting cavities, an optimization of tritium production versus proton energy is in order, especially in view of the expected savings on operation cost. It has been determined ${ }^{10}$ that the $3 / 8$ tritium production goal can also be met with a total beam power of $180 \mathrm{MW}$ at the proton energy of $1.8 \mathrm{GeV}$. As stated above, this can be accomplished with four linacs each with an average beam current of 25 $\mathrm{mA}$. For reliability and redundancy, an ion source current of $30 \mathrm{~mA}$ is then proposed, well within present technical capabilities.

\section{General Layout}

A scenario with multiple linacs and targets is shown schematically in Figure 2 . It is made of four 1.8-GeV linacs, each accelerating an average beam current of $25 \mathrm{~mA}$. Each linac is followed by a straight-ahead transport for beam disposal. Each linac feeds one of two targets placed on each side of the beam dump. Beam is taken to the targets by transport lines running at the same linac elevation. The layout shown in Figure 2 is optimized so as to require only the design of a single line for transport to the target, and of a single line to the beam dump. There are a total of five target sta- 
tions, which may be designed around different principles of tritium production from spallation neutrons.

Since the beam energy is higher, targets for the generation of neutrons by spallation are deeper. But, because the total beam power on a target is four times smaller, the footprint has also an area four times smaller. This simplifies the design of the beam expander, beam manipulation and target handling.

Reliability and redundancy is obvious from the inspection of Figure 2. Beam availability on targets, and, thus, of tritium production is greatly increased. Failure or maintenance of any one component will have minimum impact on the operation of the entire facility.

Furthermore, the modular approach will allow construction of various components, namely accelerators, targets and beam transport lines, in stages. Decision on the continuation of the project to the final 3/8-goal configuration (or beyond), modification, and change of siting can then proceed in sequence as experience with hands-on cost, operation, performance, and need is acquired. This will also ensure prompt delivery of tritium as required.

\section{A Modular Linac}

Beam power can be expressed as the product of beam energy $E$ and intensity $I$, that is

$P_{0}=E I$

The two quantities, $\mathrm{E}$ and $\mathrm{I}$, can be traded against each other, as long as $\mathrm{P}_{0}$ remains roughly the same. Their choice depends on the expected accelerator performance and cost, and on the target yield of neutrons and therefore tritium. As an example, which is believed close to optimum, the beam power of $\mathrm{P}_{0}=45 \mathrm{MW}$ requires a beam current of $25 \mathrm{~mA}$ and an energy of $1.8 \mathrm{GeV}$.

An example of a superconducting linac is outlined in Figure 3, which has been extrapolated from recent ESS studies ${ }^{11}$. It is made of three parts: the front-end, which includes the ion source and the RFQ's, the low- $\beta$ section, which may be made of either normal or superconducting cavities, and the high- $\beta$ section which is definitively superconducting. Major parameters are given in Table 5.

The positive-ion source sits on a platform at $50-\mathrm{kV}$ potential and generates an average current of $30 \mathrm{~mA}$. The beam is immediately injected into a first RFQ at $350 \mathrm{MHz}$ for acceleration to about 2 $\mathrm{MeV}$, and then into a second RFQ at the same frequency for acceleration to $5 \mathrm{MeV}$ where $\beta=$ 0.10 . Depending on the magnitude of the space-charge effects and on their control in the early part of acceleration and focussing, a beam current in the range $25 \mathrm{~mA}$ will be effectively transmitted beyond the RFQs. Beam chopping, which is needed for pulsed neutron sources, is not required for the continuous mode of operation. The beam is then injected and accelerated into the low- $\beta$ section to $100 \mathrm{MeV}$, when the proton velocity is large enough $(\beta=0.43)$ for a more effective acceleration in the subsequent high- $\beta$ section. Both sections operate at $350 \mathrm{MHz}$ (as the RFQ's). All cavities have an internal aperture of $100 \mathrm{~mm}$. With the same frequency of $350 \mathrm{MHz}$ from one end to the other of the accelerator, all rf buckets are filled with $4.4 \times 10^{8}$ protons, four times less than 
the corresponding value of the proposed 200-MW APT Linac, and slightly less than the particle count in the LAMPF buckets.

The design described here is just a feasible example. Other configurations are certainly possible. For instance, the two RFQ's may be replaced by a single one; different intermediate energies between 70 and $150 \mathrm{MeV}$ can be selected, and so on. But it is important that the design allows for conservatism to reduce technical risk and guarantee reliability and availability.

The low- $\beta$ section can be made of normal-conducting or superconducting cavities. Both options are being considered by different groups ${ }^{11,12}$. The high- $\beta$ section is superconducting as it is being explored by the ESS group ${ }^{11}$. In the case of normal-conducting $\mathrm{rf}$ system the optimal accelerating gradient is close to 1 or $2 \mathrm{MV} / \mathrm{m}$, whereas the superconducting solution allows higher accelerating gradients, in proximity of 5 to $10 \mathrm{MV} / \mathrm{m}$. The actual acceleration gradient will be diminished by the need for inserting space for the focussing quadrupoles, tank interconnections, pumps, etc.. This factor can be optimized to about $50 \%$, so that a total energy gain of $1.7 \mathrm{GeV}$ in the superconducting linac may require a total length of about $400 \mathrm{~m}$.

\section{Superconducting Linacs}

Superconducting technology has some obvious advantages for the continuous mode of operation, which can be summarized as higher accelerating gradient and negligible dissipated power ${ }^{13}$. At the same time it requires a cryogenic system which bears some cost both for construction and operation. The superconducting technology has been demonstrated successfully in several facilities ${ }^{14}$. Capitalizing on the results at Newman Laboratory of Cornell University, the Continuous Electron Beam Accelerator Facility in Virginia accelerates electrons in two 0.5-GeV linacs, joined together by magnet arcs, at $1.5 \mathrm{GHz}$ with a cavity iris of $70 \mathrm{~mm}$ and an effective average gradient of $5 \mathrm{MV} / \mathrm{m}$. In Europe, superconducting cavities at $350 \mathrm{MHz}$ have been added to the LEP collider, where there are also plans to replace the entire accelerating system with similar rf cavities for a total of about $1 \mathrm{GV}$. A large number of superconducting if cavities at $500 \mathrm{MHz}$ have been added in the HERA electron storage ring (Hamburg) and in the TRISTAN electron-positron collider at KEK in Japan. This technology (see Table 6) has been developed for the acceleration of electron beams which have a velocity $\beta$ very close to unity, and for a continuous mode of operation. When application to acceleration of protons is proposed, the most immediate question is that one needs to demonstrate the capability of design modulation to accommodate the change of beam velocity and then the continuous mode of acceleration. Indeed protons have not yet been accelerated in superconducting linacs.

But there are several examples of superconducting low-energy linacs for the acceleration of heavy-ions ${ }^{15}$. A comprehensive list is given in Table 7. Most notable ${ }^{16}$ is ALPI, shown in Figure 4. The superconducting-cavity complex is located at Legnaro (Padua, Italy), with a total of 90 MV. It was just recently brought in operation. The system is made of 80 and $160 \mathrm{MHz}$ quarterwavelength cavities, shown in Figure 5, capable of operating with ion velocities as low as $\beta=$ 0.05 . At the moment the cavities are made of lead-coated copper and have a modest gradient of 2 $4 \mathrm{MV} / \mathrm{m}$.

A few superconducting niobium cavities at $350 \mathrm{MHz}$ have been designed and operated at 
Argonne ${ }^{17}$, some of which are shown in Figures 6 and 7 , for a velocity range between $\beta=0.1$ and 0.8 . These cavities are typically made of a single cell with one or two gaps depending on their geometry and dimension. At large velocities, $\beta>0.4$, cavities can be made of two or more cells for better acceleration and power distribution. The accelerators listed in Table 7 are examples of operating superconducting low- $\beta$ linacs that, in principle, can also accelerate protons from an $\mathrm{RFQ}$. They typically accelerate only modest beam intensities, and it remains to demonstrate acceleration of intense beams. The merit of a low- $\beta$ superconducting linac versus a normal-conducting DTL should be explored more in detail, especially considering the beam current that ought to be accelerated.

There is another important advantage in the use of superconducting cavities. They can be individually powered and phased with respect to each other, allowing a considerable flexibility in tuning and redundancy. In the event that one cavity should fail, acceleration can still proceed by simply readjusting the phase of the neighboring cavities. Moreover, elements like quadrupole magnets for the focussing of the transverse motion, can be easily interspersed with the rf cavities at the required spacing. There is always the freedom to choose normal-conducting magnets, as done in ALPI with modules shown in Figures 4 and 8 , if there should be a concern about beam activation and the need for easy maintenance and replacement, or to take advantage of superconductivity by placing all elements in the same cryogenic modules, as recently proposed ${ }^{18}$ by ANL, and shown in Figure 9.

As noted above, with superconducting cavities the dissipated power in the cavity wall is eliminated. Contrary to the experience with electron beams, because of the considerably lower intensity per beam bunch and the longer length of the bunches, the power loss to high-order modes (HOM) is also negligible. On the other hand, there is the relative modest penalty of the power being dissipated in the refrigeration system.

For simplicity, without prejudicing on future optimization design, we shall assume next that the low- $\beta$ section is a normal-conducting DTL. The following design considerations are based on this assumption.

\section{Total Length of a Single 45-MW Linac}

The total length of a single linac can be estimated as follows

$L=L_{F E}+E_{\text {int }} /(g G \cos \phi)_{\text {low }-\beta}+\left(E_{\text {fin }}-E_{\text {int }}\right) /(g G \cos \phi)_{\text {high }-\beta}$,

where $L_{F E} \sim 10 \mathrm{~m}$ is the length of the ion source plus the RFQ's. A normal-conducting low- $\beta$ section, which accelerates at the if phase angle $\phi \sim 30^{\circ}$ to the intermediate energy $E_{\text {int }}=100 \mathrm{MeV}$ with a gradient of $G=1.5 \mathrm{MV} / \mathrm{m}$ diluted by a packing factor (for focusing elements) of $g=0.8$, is about $92 \mathrm{~m}$ long. Similarly, the superconducting high $-\beta$ section, with a gradient $\mathrm{G}=10 \mathrm{MV} / \mathrm{m}$ and a dilution factor $g=0.5$ at the rf phase $\phi \sim 30^{\circ}$, is about $393 \mathrm{~m}$ long for a final energy of $E_{\text {fin }}=$ $1.8 \mathrm{GeV}$. The entire linac is thus about $494 \mathrm{~m}$ long. 


\section{Total rf Power Requirement for a 45-MW Linac}

The total if power is the sum of beam power, cavity-wall dissipated power, and cavity-filling power ${ }^{11,19,20}$, namely

$P_{r f}=P_{\text {beam }}+P_{\text {diss }}+P_{\text {fill }}$.

By definition $\mathrm{P}_{\text {beam }}=1.8 \mathrm{GeV} \times 25 \mathrm{~mA}=45 \mathrm{MW}$.

The dissipated power on the cavity walls is:

$\mathrm{P}_{\text {diss }}=\mathrm{G} \Delta \mathrm{E} /(\mathrm{R} / \mathrm{Q}) \mathrm{Q}_{0} \cos \phi$,

where $\Delta \mathrm{E}$ is the energy gain, $\mathrm{R} / \mathrm{Q} \sim 400-800 \mathrm{ohm} / \mathrm{m}$ the characteristic impedance, and $\mathrm{Q}_{0} \sim 5 \times 10^{9}$ the figure of merit in the high- $\beta$ section. In the normal-conducting DTL the characteristic impedance $\mathrm{R} / \mathrm{Q} \sim 1000-2000 \mathrm{ohm} / \mathrm{m}$ and the figure of merit $\mathrm{Q}_{0} \sim 1 \times 10^{5}$. Thus $\mathrm{P}_{\text {diss }}=1.1 \mathrm{MW}$ in the low- $\beta$ section, and only $7 \mathrm{~kW}$ in the high $-\beta$ section.

The power required for filling the cavities, after they have been partially emptied by the passage of beam bunches, is given by the ratio of the total cavity energy

$\mathrm{U}=\left(2 \times 10^{-4}\right.$ Joules $) \lambda^{2} \mathrm{G} \Delta \mathrm{E} / \cos \phi$,

where $\lambda=85.66 \mathrm{~cm}$ is the rf wavelength, $\mathrm{G}$ is given in $\mathrm{MV} / \mathrm{m}$, and $\Delta \mathrm{E}$ in $\mathrm{MeV}$, to the filling time $\tau_{\mathrm{F}}$, which is about four times the decay time $\tau_{\mathrm{D}}$ for the normal-conducting cavities, and about ten times $\tau_{D}$ for the superconducting cavities;

$\tau_{\mathrm{D}}=\mathrm{Q}_{0} \mathrm{P}_{\mathrm{diss}} / \pi \mathrm{f} \mathrm{P}_{\text {beam }}$,

where $\mathrm{f}=350 \mathrm{MHz}$. It results that $\mathrm{P}_{\text {fill }}=1.5 \mathrm{MW}$ for the low- $\beta$ section and $4.1 \mathrm{MW}$ for the high- $\beta$ section.

The total rf power requirement for the operation of a single 45-MW Linac is thus $P_{\mathrm{rf}}=52 \mathrm{MW}$.

\section{Total Cryogenic Power Requirement for a 45-MW Linac}

The refrigeration system absorbs the following sources of heat ${ }^{19,20}$ : power dissipated on the cavity walls, static heat loss, and losses to cavity high-order modes (HOM), namely:

$\mathrm{P}_{\text {cry }}=\mathrm{P}_{\text {diss }}+\mathrm{P}_{\text {sta }}+\mathrm{P}_{\mathrm{HOM}}$.

It is assumed that only the high- $\beta$ section is superconducting at the temperature of $4.2^{0} \mathrm{~K}$. Moreover it is assumed that the total length of $393 \mathrm{~m}$ of the section is under refrigeration. It has already been determined that $P_{\text {diss }}=7 \mathrm{~kW}$. Assuming a conservative static loss of $5 \mathrm{~W} / \mathrm{m}$, it is also derived that $\mathrm{P}_{\text {sta }}=2 \mathrm{~kW}$. The losses to the high-order modes can be estimated from 
$P_{\text {HOM }}=\left(3.3 \times 10^{-7} \mathrm{~W} /\right.$ cell $) \mathrm{n}_{\text {cell }} I \mathrm{f}^{2}$,

where the beam average current $I$ is in $\mathrm{mA}$ and the rf frequency $\mathrm{f}$ in $\mathrm{MHz}$. Cell length varies between 20 and $40 \mathrm{~cm}$; there are thus about $n_{\text {cell }}=700$ rf cells which gives $P_{\text {HOM }}=0.7 \mathrm{~kW}$. The total required refrigeration power is thus about $P_{\text {cry }}=9.2 \mathrm{~kW}$.

\section{Total AC Power Requirement for a 45-MW Linac}

The total requirement of $\mathrm{AC}$ power can be broken down as the contribution to the if power and to the cryogenic system.

The conversion efficiency from $\mathrm{AC}$ to if power is given by the following product factors: the conversion efficiency from.AC.to DC of about $99 \%$, the direct klystron efficiency of about $65 \%$ and the transmission efficiency in the waveguide which here is taken to be $90 \%$. Thus the total conversion efficiency is $\eta_{\mathrm{rf}}=58 \%$.

On the other hand, the cryogenic efficiency for a $4.2^{\circ} \mathrm{K}$ plant is considerably low, $\eta_{\mathrm{cry}}=0.4 \%$.

We can thus estimate the total $\mathrm{AC}$ power requirement to operate the a single 45-MW linac:

$\mathrm{P}_{\mathrm{AC}}=\mathrm{P}_{\mathrm{rf}} / \eta_{\mathrm{rf}}+\mathrm{P}_{\text {cry }} / \eta_{\text {cry }}=(92.2+2.3) \mathrm{MW}=94.5 \mathrm{MW}$.

\section{Operation Cost of a Single 45-MW Linac}

There are three components which determine the operation cost of a single linac: scientific and technical staffing, maintenance, and electric power cost. The latter has the largest contribution. The cost for electricity for the yearly operation can be determined as follows

$\mathrm{O}=(0.0665 \$ / \mathrm{kWh}) \times(365$ days $) \times(24$ hours/day $) \times \eta_{\text {avail }} \times \mathrm{P}_{\mathrm{AC}}$

where $0.0665 \$ / \mathrm{kWh}$ is the assumed electricity cost in 1994 dollars. The fraction of the year for which the linac is to be available for operation is expressed by $\eta_{\text {avail }}$. With $100 \%$ of the yearly time available, $\eta_{\text {avail }}=1$, and $O=55 \mathrm{M} \$ /$ year. This does not include target and tritium processing costs.

\section{Investment Cost of a Single 45-MW Linac}

The total capital cost for the construction of a single linac can be broken down in the following elements ${ }^{20.21}$ :

- Front-End, made of the ion source and of the RFQ's

$30 \mathrm{M} \$$

- Normal-Conducting 100-MeV DTL at $0.22 \mathrm{M} \$ / \mathrm{m}$ all inclusive (rf cavities, focussing magnets, vacuum system, tunnel, klystron gallery, etc...)

$20 \mathrm{M} \$$

- High- $\beta$ Section

at $0.29 \mathrm{M} \$ / \mathrm{m}$ all inclusive (rf cavities, focussing magnets, 
vacuum system, tunnel, klystron gallery, etc...)

$114 \mathrm{M} \$$

- Klystrons at $4 \mathrm{M} \$ / \mathrm{MW}$ of if power

$280 \mathrm{M} \$$

- Electrical Distribution at $0.14 \mathrm{M} \$ / \mathrm{MW}$ of $\mathrm{AC}$ power

$15 \mathrm{M} \$$

- Refrigeration Plant at $4 \mathrm{M} \$ / \mathrm{kW}$ of cryogenic power

$40 \mathrm{M} \$$

The total construction cost per linac is thus 420 million in 1994 dollars; of which about half is the cost of the klystrons. This amount does not include the cost for targets and tritium removal; and assumes no contingency and no escalation.

\section{Comparison of the Multiple-Linac Approach with the Single APT Linac}

Using the considerations made and the scaling formulas for cost and power given above, we can work out a comparison of the different phases of the Los Alamos APT Linac with the multiplelinac approach. The results are shown in Tables 8 and 9. Values are in 1994 dollars. Again the cost of targets has not been included in this analysis, and no allowance for contingency and escalation has teen made. It is seen that the modular approach has three clear advantages over the phased approach of the APT Linac: the operation cost is substantially lower, the tritium production is more efficient with construction phasing, and it is clearly at less technical risk.

Before a final choice is made, it is obvious that a preliminary conceptual study is needed to determine:

1. ( )ntumization of the modular approach.

2. Accelcrator performance versus beam intensity and final energy.

3 Tare't performance versus beam final energy.

4. More accurate cost and power analysis.

As examples, we have considered also few other cases of linac configurations. The procedure outIned here allows flexibility with time. Once the first module has been built, it may be found more attractuve and convenient to add more superconducting cavities to boost the beam to even larger energies. This allows trading of the number of linac modules with beam energy and linac length, for the same total beam power. Moreover, if at the same time ion sources should be developed far enough with even larger beam currents, it may also be found that by simply replacing the ion scurce and by doubling the number of if power amplifiers, one can obtain the required performance with a single superconducting linac. All these cases are compared against each other in Table 10. The last column shows a case corresponding to a very high-current ion-source; if this should the developed, it is seen that final energy can be traded against beam intensity for a more economical solution.

In summary, the construction of a first 45-MW linac module will allow phasing based on acquired experience with beam performance. A variety of solutions will then be at hand from which one can choose to minimize cost, to improve reliability and availability, and to reduce the technical risk. 


\section{Experimental Demonstration of a High-Intensity Proton Linac}

As we have seen, a single linac is made of three parts: the front-end, that is the source and the RFQs, the low-beta section, which could be normal- or super-conducting, and the high-beta section which is made of superconducting cavities. The front-end has little impact on the total cost of the accelerator (if one neglects technology development costs), but its design has crucial rclevance to the beam performance, and machine availability. The nature of the project of producing tritium requires a system which can quickly and reliably be turned on with a minimum of research and development. It is thus important to develop a prototype of a few-MW low-energy conventional front-end to demonstrate continuous mode of operation at the required beam current. The demonstration could then constitute the prototype of the actual front-end of a single linac. As shown schematically in Figure 10, it requires:

1. Development of a continuous ion source at $30 \mathrm{~mA}$ on a $50-\mathrm{kV}$ platform.

2. Development of a 2-MeV RFQ followed by a $5-\mathrm{MeV}$ RFQ both at $350 \mathrm{MHZ}$.

(As an alternative, the two RFQ's can be combined into a single device).

3. Development of a normal-conducting $20 \mathrm{MeV}-\mathrm{DTL}$ at $350 \mathrm{MHz}$.

(As an alternative, the normal-conducting accelerator stage can be entirely eliminated).

4. Development of superconducting cavities at $350 \mathrm{MHz}$ for acceleration to $40 \mathrm{MeV}$.

The cost of the experimental program ${ }^{24}$ is close to $100 \mathrm{M} \$$. A demonstration of principle can also be made with hardware available in accelerator laboratories, and would still be quite useful, even in the case the parameters do not quite match the required values, to prove acceleration of intense beams of protons in a continuous mode of operation from the low-velocity end.

\section{A 45-MW Linac for the Advanced Spallation Neutron Source}

A single proton linac which generates $45 \mathrm{MW}$ of beam power, as described above for tritium production, can produce a neutron flux by spallation exceeding that of the Advanced Neutron Source $^{7}$ of Oak Ridge based on nuclear-reactor technology. The 45-MW linac represents quite a powerful proton source when it is compared to the other pulsed spallation neutron sources which are currently under investigation. At the energy of $1.8 \mathrm{GeV}$, an intensity of $1.6 \times 10^{17}$ protons per second yields a neutron flux ${ }^{22}$ of about $10^{16}$ neutrons $/ \mathrm{cm}^{2} / \mathrm{s}$. Moreover, it is possible to generate neutron pulses of different time duration by simply pulsing the proton source. There are three conceivable modes of operation: continuous beam with $100 \%$ duty cycle, long pulses in the millisecond range, and short pulses of a few microseconds at 10 and 60 pulses per second. A layout of the Advanced Spallation Neutron Source is shown schematically in Figure 11. Because of the large beam power involved, multiple targets are required for a more efficient, safe, and reliable operation.

The full beam power can be delivered to those experiments that require continuous beam at $100 \%$ duty cycle. The target arrangement is essentially similar to the one for tritium production, but the targets are designed for other applications and to allow multiple users. By pulsing the linac at 60 $\mathrm{Hz}$ and at $15 \%$ duty cycle, it is also possible to provide neutron beams to those experiments that require long pulses, in the range of few milliseconds, at the same repetition rate. The average proton power available for this mode of operation is reduced to $6.75 \mathrm{MW}$, still very considerable. 
This mode of operation requires adding the capability of pulsing both the superconducting linac and the ion source. The beam average intensity is lower, but the peak value remains $25 \mathrm{~mA}$.

The short-pulse mode of operation, in the microsecond range, requires the inclusion of two Accumulator Rings where the proton beam is stored and compressed to the required duration, as shown in Figure 11. One ring generates beam pulses at 10 and the other at $60 \mathrm{~Hz}$. There are two fundamental limitations encountered in an Accumulator Ring: first, the total number of beam turns that can be stored should not exceed the value of a thousand. This is achieved by selecting properly the circumference of the rings and thus the revolution period. Second, the space-charge limitation, customarily expressed as the depression $\Delta v$ of the betatron tune, should not exceed 0.2 . This value is reached by allowing the beam size to increase accordingly.

To achieve a lossless multiturn injection into the rings by charge exchange, a negative-ion source feeds the linac, and the beam pulse is chopped by $60 \%$ between the two RFQ's. That generates a train of micropulses matching the rf capture in the Accumulator Rings. For the operation of one of the two rings at $60 \mathrm{~Hz}$, the duty cycle of $15 \%$ is obtained by choosing a convenient circumference of the ring to allow no more than one thousand beam turns. This yields an average beam power of $4 \mathrm{MW}$. The second ring operates at $10 \mathrm{~Hz}$; with the same duration of injection, the duty cycle is now only $2.5 \%$, and the average beam power $0.67 \mathrm{MW}$.

A preliminary design of the Accumulator Rings has been made and the main parameters are given in Table 11. It is to be noticed that both rings operate well below space-charge limit. It is then possible to develop an ion source of even larger peak current. For instance an ion source of $50 \mathrm{~mA}$ could easily double the average beam power.

\section{A Proton Source for the Production of Intense Muon Beams}

There is recently a renewed interest for a muon collider ${ }^{23}$, in the $\mathrm{TeV}$ energy range with high luminosity, for exploration of the most fundamental aspects of particle high-energy physics. This project requires a large amount of $\mu$-mesons which are not available in nature and have thus to be produced by impinging intense beams of protons on targets at an energy of about $30 \mathrm{GeV}$. Moreover muons are unstable particles and decay fast; thus, production, collection, cooling and acceleration has to proceed in a very short time before two beams of $\mu^{+}$and $\mu^{-}$are brought in collision.

The high-intensity $30-\mathrm{GeV}$ proton facility is outlined in Figure 12. A 1.8-GeV proton linac, similar to the one described above for tritium production and for the Advanced Spallation Neutron Source, is the injector to a fast-cycling 8-GeV Synchrotron (the Booster in Figure 12), which operates at the repetition rate of $30 \mathrm{~Hz}$. Because of the acceleration, the number of beam turns that can be injected into the Synchrotron is now limited to 300 to avoid excessive beam losses during the if capture. The linac is thus pulsed at $30 \mathrm{~Hz}$ and operates with a duty cycle of $2.5 \%$. To allow multiturn injection by charge exchange, a negative-ion source is feeding the linac. Beam chopping of $60 \%$ is also applied for matching the rf capture during injection into the fast-cycling Synchrotron. The peak current being accelerated to $1.8 \mathrm{GeV}$ is $25 \mathrm{~mA}$, but the average current is considerably lower. The 8-GeV Synchrotron (the Booster) has the same size and design of the Accumulator Ring described earlier, except that now the bending field is ramped to allow for acceleration. 
At the end of the acceleration, a beam pulse is transferred in a Holding Ring, shown in Figure 12 , held at constant field, otherwise of the same size and design of the Booster. The beam is stored circulating, waiting that a second pulse is accelerated to the same energy. Then both beam pulses are injected into a second fast-cycling Synchrotron (the Main Ring of Figure 12), which accelerates to the final energy of $30 \mathrm{GeV}$ at the repetition rate of $15 \mathrm{~Hz}$. The Main Ring has a circumference twice that of the Booster. At the end of the acceleration cycle, the beam is extracted from the Main Ring and used on a sequence of targets and transport channels for the production of muons. Taking the value of 0.1 for the yield of protons to a pair of muons, the facility generates about $10^{14} \mu$-pairs per second.

This lacility can be used of course also for a variety of other applications in nuclear and highenergy physics, like neutrino physics, production of kaons and antiprotons, study of CP violation, and $w$ on. Major parameters for the Accelerators are listed in Table 12.

\section{Conclusions}

Wi has cxplored a Modular (or Multiple) Linac approach for Tritium Production (MLTP) as "ppuxed w the single APT Linac proposed by the Los Alamos team. ()ur intent has been to reduce the ammunt of lechnical risk involved in the project, considering its size and magnitude. A Multiple Linsi approach, in our view, provides modularity, more flexibility, better reliability, and improv. d abilability. For the attainment of the same goal, we have also proposed the use of superunductung cavities to eliminate, or at least to reduce, constraints such as linac length, accelerdlunn :radient. power consumption, and difficulty of operation. Nevertheless, a 45-MW Linac sull reprevents a considerable extrapolation, an order of magnitude above what is been investi:alled the $x$ days for spallation neutron sources, and considerably more above currently demonstras:d lie hnology. Thus, our proposal should be taken cautiously. Once the concept of a multiple, riduced reyurrement linac approach is accepted, a more realistic feasibility design needs to be dim.

A $45-.114$ h hace of an energy of lew GeV is also a powerful tool for basic and energy research in a variely 11 liclds. The research community has, of course, quite some interest in the exploitation of such d lacilit!. even and especially if it is made of only one of the four linacs, and would seek the full share of the demonstration program. In fact the know-how for developing this accelerator is currently sery limited and essentially concentrated in large accelerator DOE laboratories. It seems obvuus that in the case that such a project be authorized and funded, the demonstration of the required lechnolugy can and should take place in DOE laboratories. If successful, this would result in a first stage availability of the facility to the research community, and subsequently transferrng of the acquired technology to industry for applications like tritium production.

\section{Acknowledgments}

The author is grateful to the Brovkhaven APT team for the continuous support and encouragement to undertake this study. He also thanks the technical stafif of the Argonne National Laboratory, of the Continuous Electron Beam Accelerator Facility, and of the Newman Laboratory of Cornell University for discussions on superconducting cavities. Finally, interaction with the Raytheon Company has been greatly appreciated for having stimulated this research. 


\section{References}

1. APT Accelerator Topical Report, LA-12668-MS. Los Alamos National Laboratory. Sep. 1993

2. G. Lawrence, Accelerator Design Overview, LLNL Review of APT, Dec. 6-8, 1994.

3. A. G. Ruggiero, Review of APT Linac, Brookhaven National Laboratory, January 10, 1994.

4. Proceedings of the Workshop on Ion Source Issues Relevant to a Pulsed Spallation Neutron Source. Lawrence Berkeley Laboratory, October 24-26, 1994.

5. H. Klein, Spallation Neutron Sources, Presented at 1994 Linear Accelerator Conference, Tsukuba, Japan, August 21-26, 1994.

6. G. Bauer, Die Spallationsneutronenquelle SINQ, PSI, Villingen, Switzerland.

7. F. J. Peretz et al., Advanced Neutron Source Conceptual Design Summary, ORNL/TM-12184, Martin Marietta Energy Systems, ORNL, September 1992.

8. 5-MW Pulsed Spallation Neutron Source, Brookhaven National Laboratory Interdepartmental Study, BNL-60678, June 1994.

9. H. Lengeler, Proposals for Spallation Neutron Sources in Europe, Presented at the 1994 European Particle Accelerator Conference, London, United Kingdom, June 30-July 5, 1994.

10. G. VanTuyle, private communication, BNL December 1994.

11. H. Heinrichs, Room Temperature Vs Superconducting Linacs, ICANS 12, Rutherford Appleton Laboratory Report Number 94-025, Volume 2, page A-144. 24-28 May, 1993.

12. J. R. Delayen et al., Development of High-Current Superconducting Accelerators at Argonne National Laboratory, Proceedings of the 6th Workshop on RF Superconductivity, CEBAF, 4-9 October, 1993.

13. H. Padamsee, K. W. Shepard, R. Sundelin, Physics and Accelerator Applications of rf Superconductivity, Annu. Rev. Nucl. Part. Sci. 1993. 43 p. 635-686.

14. H. Padamsee, An Overview of RF Superconductivity Research, presented at the Applied Super Conductivity Conference, Oct. 16-20, 1994, Boston, MA.

15. J. R. Delayen, Superconducting Linac Low $\beta$ Section, Proceedings of the International Workshop on High Intensity Proton Linear Accelerators for Future Spallation Neutron Sources, Vol. II, page 430, Witten, Germany, May 31-June 4, 1993.

16.L. Badan et al., Review of ALPI, Presented by A. Lombardi at the 1994 European Particle Accelerator Conference, London, United Kingdom, June 30-July 5, 1994.

17. J. R. Delayen et al., Design Considerations for High-Current Superconducting Ion Linacs, Proceedings of the 1993 Particle Accelerator Conference, Washington, D.C., 17-20 May 1993.

18. J. R. Delayen, Recent Developments in the Application of RF Superconductivity to HighBrightness and High-Gradient Ion Beam Accelerators, Proceedings of the 5th Workshop on RF Superconductivity, DESY, August 1991.

19. H. Padamsee, Superconducting RF, The Physics of Particle Accelerators, AIP Conf. Proceed. 249, Vol. 1, page 1402. 1989-90.

20. K. Bongardt, The European Spallation Source ESS, Presentations made at LANL and Fermilab, April 1994.

21. M. Prome', Conceptual Studies for a High Power Proton Linac, Presented at 1994 Linear Accelerator Conference, Tsukuba, Japan, August 21-26, 1994.

22. H. Ludwig, private communication, BNL December 1994.

23. D. Neuffer, The Muon Collider, Presented at the 1994 European Particle Accelerator Conference, London, United Kingdom, June 30-July 5, 1994.

24. A. G. Ruggiero, 4-Year Plan for Risk Reduction of the Accelerator-based Production of Tritium (APT). Brookhaven National Laboratory, January 9, 1995. 
Table 1. Demonstrated Ion Source Performance CW or Positive Ions ${ }^{4}$

\begin{tabular}{|c|c|c|c|c|c|c|c|c|}
\hline Source Type & Ion $+1=$ & $\mid \begin{array}{l}\mathrm{I}_{\text {peak }}(\mathrm{mA}) \\
(\text { protons })\end{array}$ & $\begin{array}{c}\text { Extract } \\
\text { Voltage } \\
(\mathrm{kV})\end{array}$ & $\begin{array}{c}\text { Arc Pulse } \\
\text { length } \\
\text { (ms) }\end{array}$ & $\underset{(H z)}{\text { Rep rate }}$ & $\begin{array}{c}\text { Arc Duty } \\
\text { Factor } \\
(\%)\end{array}$ & $\underset{\text { (mm-m rad) }}{\mathcal{E}_{\text {norm }}}$ & Comments \\
\hline $\begin{array}{l}\text { Volume } \\
\text { PSI } \\
\end{array}$ & + & 20 & 60 & $\mathrm{CW}$ & $\mathrm{CW}$ & 100 & $\begin{array}{l}0.3 \pi \\
(90 \%)\end{array}$ & $\begin{array}{l}\text { Modified (by PSI) Culham } \\
\text { Filament (W) } \\
\approx \mathbf{3 3 \%} \text { proton yield }\end{array}$ \\
\hline $\begin{array}{l}\text { Volume } \\
\text { LBL }\end{array}$ & + & 60 & & & & & & $\begin{array}{l}\mathrm{RF} \\
\approx 80 \% \text { proton yield }\end{array}$ \\
\hline \begin{tabular}{|l} 
Volume \\
Grumman \\
\end{tabular} & + & 44 & 42 & $\mathrm{CW}$ & $\mathrm{CW}$ & 100 & & $\underset{\approx 55 \% \text { proton yield }}{\mathrm{RF}}$ \\
\hline $\begin{array}{l}\text { Volume } \\
\text { JAERI }\end{array}$ & + & 140 & 100 & 1 & 100 & 10 & $\begin{array}{l}0.5 \pi \\
(90 \%)\end{array}$ & $\begin{array}{l}\text { Filament } \\
85 \% \text { proton yield }\end{array}$ \\
\hline $\begin{array}{l}\text { Volume } \\
\text { LANL }\end{array}$ & + & 60 & 47 & $\mathrm{CW}$ & $\mathrm{CW}$ & 100 & & $\begin{array}{l}\text { Microwave } \\
\approx 200 \mathrm{hr} \text { longevity test } \\
\mathbf{7 5 \%} \text { proton yield }\end{array}$ \\
\hline $\begin{array}{l}\text { Duoplasmatron } \\
\text { LANL }\end{array}$ & + & 30 & 35 & 1 & 120 & 12 & $\frac{0.065 \pi}{(\mathrm{rms})}$ & $\begin{array}{l}\text { Run to } 45 \text { ma at } 6 \% \text { DF } \\
\text { Directly interfaced to } \\
750 \mathrm{kV} \text { column }\end{array}$ \\
\hline $\begin{array}{l}\text { Volume } \\
\text { TRIUMF } \\
\end{array}$ & - & 12 & 25 & $\mathrm{CW}$ & $\mathrm{CW}$ & 100 & $\underset{(4 \mathrm{rms})}{0.3 \pi}$ & $\begin{array}{l}\text { Filament (Ta) } \\
\mathrm{e} / \mathrm{H}=5\end{array}$ \\
\hline $\begin{array}{l}\text { Volume } \\
\text { TRIUMIF }\end{array}$ & - & 1.6 & 25 & 3 & 60 & 20 & $\begin{array}{c}0.3 \pi \\
(4 \mathrm{rms})\end{array}$ & $\begin{array}{l}\text { Microwave } \\
\text { Good lifetime }\end{array}$ \\
\hline
\end{tabular}


Table 2. Intense Proton Sources ${ }^{5}$

\begin{tabular}{|l|l|l|c|c|c|c|}
\hline & & $\begin{array}{c}\text { Av. Current } \\
\mathrm{mA}\end{array}$ & $\begin{array}{c}\text { Energy } \\
\text { GeV }\end{array}$ & $\begin{array}{c}\text { Power } \\
\text { MW }\end{array}$ & $\begin{array}{c}\text { Duty Cycle } \\
\%\end{array}$ \\
Operating: & AGS Booster & Linac/Synchr. & 0.02 & 1.5 & 0.03 & $<1.0$ \\
\cline { 2 - 7 } & ISIS & Linac/Synchr. & 0.20 & 0.8 & 0.16 & 1.0 \\
\cline { 2 - 8 } & LANSCE & Linac & 1.0 & 0.8 & 0.8 & 7.0 \\
\hline AUSTRON & Linac/Synchr. & 0.25 & 1.6 & 0.4 & $<1.0$ \\
\hline SINQ & Cyclotron & 1.5 & 0.6 & 0.9 & 100 \\
\hline ANL & Linac/Synchr. & 0.5 & 2.0 & 1.0 & 2.5 \\
\hline NCNR & Linac/Accum. & 1.25 & 0.8 & 1.0 & 7.2 \\
\hline PSNS-BNL & Linac/Synchr. & 1.35 & 3.6 & 5 & 2.8 \\
\hline ESS & Linac/Synchr. & $3.8 / 1.7$ & $1.3 / 3.0$ & 5 & 6.6 \\
\hline ANS-Moscow & Linac/Synchr. & 0.5 & 10.0 & 5 & 5.0 \\
\hline ETA-Japan & Linac/Accum. & 10 & 1.5 & 15 & 10 \\
\hline APT & Linac & 200 & 1.0 & 200 & 100 \\
\hline
\end{tabular}


Table 3. Operating Proton Linacs in USA

\begin{tabular}{|c|c|c|c|}
\hline & BNL & Fermilab & LAMPF \\
\hline \hline Source Current & $50 \mathrm{~mA}$ & $35 \mathrm{~mA}$ & $30 \mathrm{~mA}$ \\
Voltage & $35 \mathrm{kV}$ & $750 \mathrm{kV}$ & $80 \mathrm{kV}$ \\
\hline RFQ frequency & $201 \mathrm{MHz}$ & -- & $201 \mathrm{MHz}$ \\
energy & $0.75 \mathrm{MeV}$ & -- & $2.5 \mathrm{MeV}$ \\
\hline DTL frequency & $201 \mathrm{MHz}$ & $201 \mathrm{MHz}$ & $201 \mathrm{MHz}$ \\
energy & $200 \mathrm{MeV}$ & $116 \mathrm{MeV}$ & $100 \mathrm{MeV}$ \\
\hline High- $\beta$ frequency & -- & $805 \mathrm{MHz}$ & $800 \mathrm{MHz}$ \\
energy & -- & $400 \mathrm{MeV}$ & $800 \mathrm{MeV}$ \\
\hline Duty Cycle \% & $<1.0$ & $<1.0$ & 6.7 \\
\hline
\end{tabular}




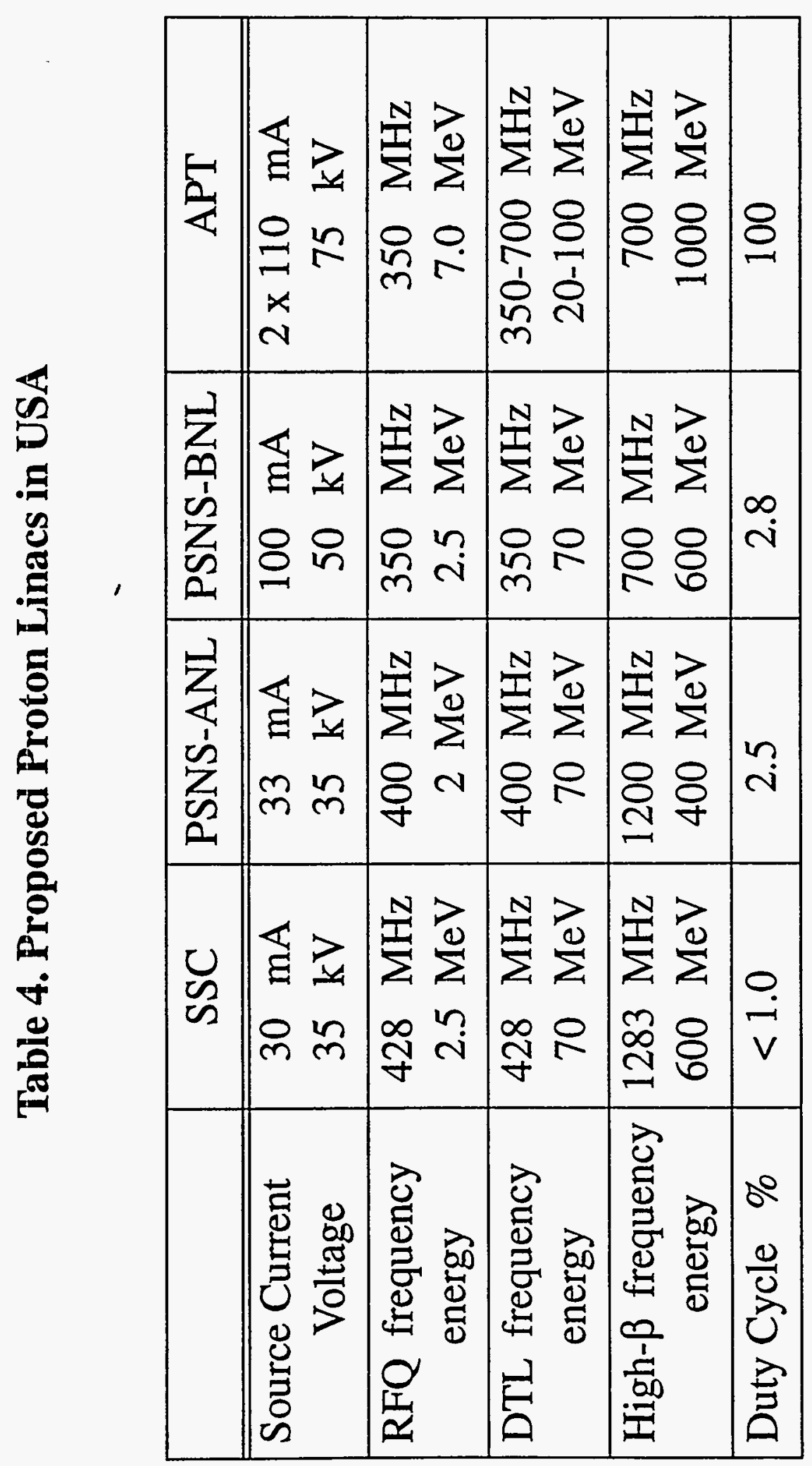




\section{Table 5. General Parameters of a Modular 45-MW Linac}

$\underline{\text { Current }} \underline{\text { Length }} \quad \underline{\text { Frequency }}$ Energy

Ion Source $30 \mathrm{~mA} \quad 2 \mathrm{~m}$

d.c.

$50 \mathrm{keV}$

RFQ1

$27 \mathrm{~mA}$

$3 \mathrm{~m}$

$350 \mathrm{MHz}$

$2 \mathrm{MeV}$

RFQ2

$25 \mathrm{~mA}$

$5 \mathrm{~m}$

$350 \mathrm{MHz}$

$5 \mathrm{MeV}$

Low - $\beta$ Section

$25 \mathrm{~mA}$

$90 \mathrm{~m}$

$350 \mathrm{MHz}$

$100 \mathrm{MeV}$

DTL normal-conducting. Gradient 1.5 MV/m. Packing Factor 0.8

High - $\beta$ Section

$25 \mathrm{~mA}$

$390 \mathrm{~m}$

$350 \mathrm{MHz}$

$1.8 \mathrm{GeV}$

Superconducting Cavities. Gradient $10 \mathrm{MV} / \mathrm{m}$. Packing Factor 0.5.

Accelerating rf Phase

Number of Protons per rf Bucket

Cavity Internal Diameter $30^{\circ}$

$4.4 \times 10^{8}$

$10 \mathrm{~cm}$ 


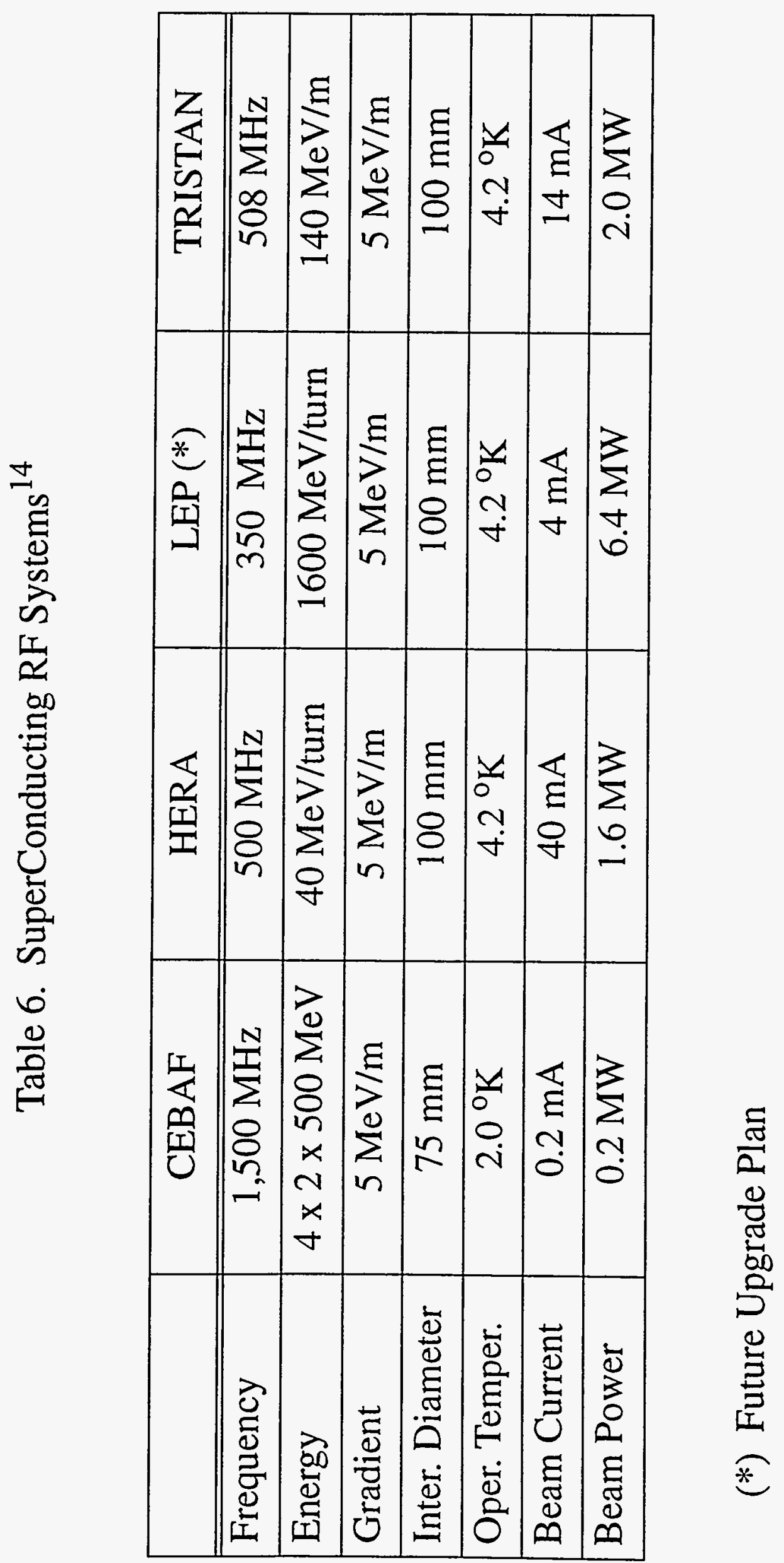


Table 7. Demonstrated Superconducting Heavy-Ion Linac Performance ${ }^{15}$

\begin{tabular}{|l|l|c|r|c|}
\hline \multicolumn{1}{|c|}{ Laboratory } & Material & Cavities & \multicolumn{1}{c|}{ Gradient } & Commissioned \\
\hline \hline Argonne / ATLAS & $\mathrm{Nb}$ & 46 & $2-4 \mathrm{MV} / \mathrm{m}$ & 1978 \\
\hline $\begin{array}{l}\text { Stony Brook } \\
\text { SUNYLAC }\end{array}$ & $\mathrm{Pb}-\mathrm{Cu}$ & 56 & $2-2.5 \mathrm{MV} / \mathrm{m}$ & 1983 \\
\hline SACLAY / France & $\mathrm{Nb}$ & 50 & $2.2 \mathrm{MV} / \mathrm{m}$ & 1987 \\
\hline Univ. Washington & $\mathrm{Pb}-\mathrm{Cu}$ & 36 & $3 \mathrm{MV} / \mathrm{m}$ & 1987 \\
\hline Florida State Univ. & $\mathrm{Nb}$ & 14 & $2-3 \mathrm{MV} / \mathrm{m}$ & 1987 \\
\hline JAERI / Japan & $\mathrm{Nb}$ & 44 & $7 \mathrm{MV} / \mathrm{m}$ & 1994 \\
\hline ALPI / Italy & $\mathrm{Pb}-\mathrm{Cu}$ & 35 & $2-4 \mathrm{MV} / \mathrm{m}$ & 1994 \\
\hline
\end{tabular}


Table 8. Comparison of Modular Linacs versus APT Linac

\begin{tabular}{|l|c|c|}
\hline & Modular Linac & APT \\
\hline \hline Number of Modules & 4 & 1 \\
\hline \hline Source Current & $30 \mathrm{~mA}$ & $(2 \times) 110 \mathrm{~mA}$ \\
\hline Output Current & $25 \mathrm{~mA}$ & $(2 \times) 100 \mathrm{~mA}$ \\
\hline \hline RFQ 1 & $350 \mathrm{MHz} \quad 2 \mathrm{MeV}$ & $350 \mathrm{MHz}(2 \mathrm{x}) 7 \mathrm{MeV}$ \\
\hline RFQ 2 & $350 \mathrm{MHz} \quad 5 \mathrm{MeV}$ & none \\
\hline \hline DTL & $350 \mathrm{MHz} 100 \mathrm{MeV}$ & $350 \mathrm{MHz} \quad(2 \times) 20 \mathrm{MeV}$ \\
\hline Funnel & none & yes \\
\hline BCDTL & none & $700 \mathrm{MHz} 100 \mathrm{MeV}$ \\
\hline \hline High - $\beta$ Section & s.c. $350 \mathrm{MHz} 1.8 \mathrm{GeV}$ & n.c. $700 \mathrm{MHz} 1.0 \mathrm{GeV}$ \\
\hline \hline Permanent Magnets & possible use & no \\
\hline Cavity Internal Diameter & $10 \mathrm{~cm}$ & $5 \mathrm{~cm}$ \\
\hline Protons / Bunch $(*)$ & $0.44 \times 10^{9}$ & $1.8 \times 10^{9}$ \\
\hline Beam Halo & less relevant & very relevant \\
\hline \hline Total Length of Linac & $495 \mathrm{~m}$ & $1180 \mathrm{~m}$ \\
\hline rf Power / Linac & $52 \mathrm{MW}$ & $254 \mathrm{MW}$ \\
\hline Cryogenic Power / Linac & $9 \mathrm{~kW}$ & none required \\
\hline
\end{tabular}

(*) all buckets are full 
Table 9. Comparison between APT Linac and Modular Linacs

\begin{tabular}{|l||c|c||c|c||c|c|}
\hline \multirow{2}{*}{ Tritium Production } & \multicolumn{2}{c||}{$3 / 32$} & \multicolumn{2}{c|}{$3 / 16$} & \multicolumn{2}{c|}{$3 / 8$} \\
\hline & APT-Linac & Modular & APT-Linac & Modular & APT-Linac & Modular \\
\hline \hline No. of Linacs & 1 & 1 & 1 & 2 & 1 & 4 \\
\hline Beam Energy & $500 \mathrm{MeV}$ & $1800 \mathrm{MeV}$ & $1000 \mathrm{MeV}$ & $1800 \mathrm{MeV}$ & $1000 \mathrm{MeV}$ & $1800 \mathrm{MeV}$ \\
\hline Beam Intensity & $100 \mathrm{~mA}$ & $1 \times 25 \mathrm{~mA}$ & $100 \mathrm{~mA}$ & $2 \times 25 \mathrm{~mA}$ & $2 \times 100 \mathrm{~mA}$ & $4 \times 25 \mathrm{~mA}$ \\
\hline Beam Power & $50 \mathrm{MW}$ & $1 \times 45 \mathrm{MW}$ & $100 \mathrm{MW}$ & $2 \times 45 \mathrm{MW}$ & $200 \mathrm{MW}$ & $4 \times 45 \mathrm{MW}$ \\
\hline Length of Linac & $580 \mathrm{~m}$ & $495 \mathrm{~m}$ & $1180 \mathrm{~m}$ & $495 \mathrm{~m}$ & $1180 \mathrm{~m}$ & $495 \mathrm{~m}$ \\
\hline Funnel & no & no & no & no & yes & no \\
\hline rf Power & $71 \mathrm{MW}$ & $52 \mathrm{MW}$ & $139 \mathrm{MW}$ & $104 \mathrm{MW}$ & $256 \mathrm{MW}$ & $207 \mathrm{MW}$ \\
\hline Cryo-Power & -- & $9.2 \mathrm{~kW}$ & -- & $18.4 \mathrm{~kW}$ & -- & $36.7 \mathrm{~kW}$ \\
\hline AC-Power & $123 \mathrm{MW}$ & $92 \mathrm{MW}$ & $240 \mathrm{MW}$ & $183 \mathrm{MW}$ & $443 \mathrm{MW}$ & $367 \mathrm{MW}$ \\
\hline Capital Cost & $460 \mathrm{M} \$$ & $420 \mathrm{M} \$$ & $880 \mathrm{M} \$$ & $840 \mathrm{M} \$$ & $1400 \mathrm{M} \$$ & $1680 \mathrm{M} \$$ \\
\hline Operation Cost $(*)$ & $72 \mathrm{M} \$ / \mathrm{y}$ & $53 \mathrm{M} \$ / \mathrm{y}$ & $140 \mathrm{M} \$ / \mathrm{y}$ & $107 \mathrm{M} \$ / \mathrm{y}$ & $258 \mathrm{M} \$ / \mathrm{y}$ & $214 \mathrm{M} \$ / \mathrm{y}$ \\
\hline 40 -year Cost & $3.3 \mathrm{~B} \$$ & $2.6 \mathrm{~B} \$$ & $6.5 \mathrm{~B} \$$ & $5.1 \mathrm{~B} \$$ & $11.7 \mathrm{~B} \$$ & $10.2 \mathrm{~B} \$$ \\
\hline
\end{tabular}

$\left(^{*}\right)$ Based on 6.65 cents/kWh and $100 \%$ availability. 
Table 10. Comparison of Different Linac Scenarios

\begin{tabular}{|l|c|c|c|c|c|}
\hline & APT & $\begin{array}{c}1.8 \mathrm{GeV} \\
\text { Modular Linacs }\end{array}$ & $\begin{array}{c}3.6 \mathrm{GeV} \\
\text { Modular Linacs }\end{array}$ & $\begin{array}{c}3.6 \mathrm{GeV} \\
\text { Single Linac }\end{array}$ & $\begin{array}{c}2.0 \mathrm{GeV} \\
\text { Single Linac }\end{array}$ \\
\hline \hline Technology & norm. conducting & superconducting & superconducting & superconducting & superconducting \\
\hline Number of Linacs & 1 & 4 & 2 & 1 & 1 \\
\hline Energy & $1000 \mathrm{MeV}$ & $1800 \mathrm{MeV}$ & $3600 \mathrm{MeV}$ & $3600 \mathrm{MeV}$ & $2000 \mathrm{MeV}$ \\
\hline Beam Intensity & $200 \mathrm{~mA}$ & $25 \mathrm{~mA}$ & $25 \mathrm{~mA}$ & $50 \mathrm{~mA}$ & $80 \mathrm{~mA}$ \\
\hline Power & $200 \mathrm{MW}$ & $180 \mathrm{MW}$ & $180 \mathrm{MW}$ & $180 \mathrm{MW}$ & $160 \mathrm{MW}$ \\
\hline Total Length & $1182 \mathrm{~m}$ & $494 \mathrm{~m}$ & $910 \mathrm{~m}$ & $910 \mathrm{~m}$ & $540 \mathrm{~m}$ \\
\hline rf Power & $256 \mathrm{MW}$ & $207 \mathrm{MW}$ & $202 \mathrm{MW}$ & $201 \mathrm{MW}$ & $181 \mathrm{MW}$ \\
\hline Cryogenic Power & -- & $37 \mathrm{~kW}$ & $38 \mathrm{~kW}$ & $20 \mathrm{~kW}$ & $12 \mathrm{~kW}$ \\
\hline AC Power & $443 \mathrm{MW}$ & $367 \mathrm{MW}$ & $359 \mathrm{MW}$ & $352 \mathrm{MW}$ & $315 \mathrm{MW}$ \\
\hline Capital Cost & $1406 \mathrm{M} \$$ & $1683 \mathrm{M} \$$ & $1579 \mathrm{M} \$$ & $1219 \mathrm{M} \$$ & $992 \mathrm{M} \$$ \\
\hline Operation Cost & $258 \mathrm{M} \$ /$ year & $214 \mathrm{M} \$ /$ year & $209 \mathrm{M} \$ /$ year & $205 \mathrm{M} \$ /$ year & $184 \mathrm{M} \$ /$ year \\
\hline 40-Year Cost & $11.72 \mathrm{~B} \$$ & $10.23 \mathrm{~B} \$$ & $9.94 \mathrm{~B} \$$ & $9.43 \mathrm{~B} \$$ & $8.34 \mathrm{~B} \$$ \\
\hline
\end{tabular}


Table 11. Accumulator Ring Parameters for the Advanced Spallation Neutron Source

Circumference

$726.4 \mathrm{~m}$

Kinetıc Energy

$1.8 \mathrm{GeV}$

Bending Radius

$42.8 \mathrm{~m}$

Bending Field

$2.0 \mathrm{kG}$

Revolution Period

$2.6 \mu \mathrm{s}$

Number of Turns Injected

Harmonic Number, Number of Bunches

970

Protons per Bunch

4

Bunch Area

$0.6 \times 10^{14}$

$8 \mathrm{eV}-\mathrm{s}$

Betatron Emittance, full normalized, $\mathrm{H} \& \mathrm{~V}$

$260 \pi \mathrm{mm}$ mrad

Tramsition Energy, $\gamma_{T}$

18.2

if firequency

$1.55 \mathrm{MHz}$

it Peak Voltage

$300 \mathrm{kV}$

Sinchrotron Tune, $Q_{s}$

0.003

Bunch Length, rms

$52 \mathrm{~ns}$

Bunch Momentum Spread, rms

$0.34 \%$

Buchet Area

$26 \mathrm{eV}$-s

Buchet Height

$\pm 1.3 \%$

Space-ChargeTune-Shift, $\Delta v$

0.13

Repetition Rate

$10 / 60 \mathrm{~Hz}$

Duly Cycle

$2.5 / 15 \%$

Alerage Beam Power

$6.7 / 4.0 \mathrm{MW}$

Average Beam Current

$0.375 / 2.25 \mathrm{~mA}$ 
Table 12. Accelerator Parameters for the Advanced Proton Source

\section{Booster

\author{
Holding Ring
}

Circumference, $\mathrm{m}$

Repetition Rate, $\mathrm{Hz}$

Duty Cycle, in \%

Kinetic Energy (GeV) @ Injection

@ Extraction

Bending Radius, $\mathrm{m}$

Bending Field (kG) @ Injection

(a) Extraction

max. Field Variation, T/s

Number of Turns Injected

Harmonic Number, Number of Bunches

Protons per Bunch

Bunch Area, eV-s

Norm. Betatron Emittance, $\pi \mathrm{mm}$ mrad

Transition Energy, $\gamma_{\Gamma}$

rf Frequency, $\mathrm{MHz}$

rf Peak Voltage, MV

rf Peak Power, MW

$\max$ Synchrotron Tune, $Q_{S}$

Space-Charge Tune-Shift, $\Delta v$

rms Bunch Length @ Extraction, ns

Average Beam Power, MW

Average Beam Current, mA
726.4

$\begin{array}{rr}726.4 & 726.4 \\ 30 & \text { d.c. } \\ 2.5 & -- \\ 1.8 & 8.0 \\ 8.0 & -- \\ 42.8 & 42.8 \\ 2.00 & 6.91 \\ 6.91 & -- \\ 46.3 & \text { d.c. } \\ 320 & \text { single-turn } \\ 4 & 4 \\ 2 \times 10^{1.3} & 2 \times 10^{13} \\ 3.0 & 6.0 \\ 120 & 120 \\ 18.2 & 18.2 \\ 1.51-1.60 & 1.60 \\ 1.8 & 0.2 \\ 7.5 & -- \\ 0.0035 & 0.0(0) 34 \\ 0.17 & 0.025 \\ 10 & 18 \\ 3.0 & 3.0 \\ 0.38 & 0.38\end{array}$

726.4

1452.8

15

$8 \overline{0}$

30.0

85.6

3.46

12.06

40.4

single-turn

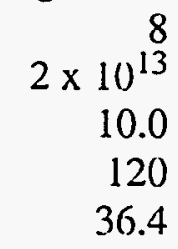

$1.60-1.61$

5.6

27

0.0011

0.042

18

5

11.5

0.38 


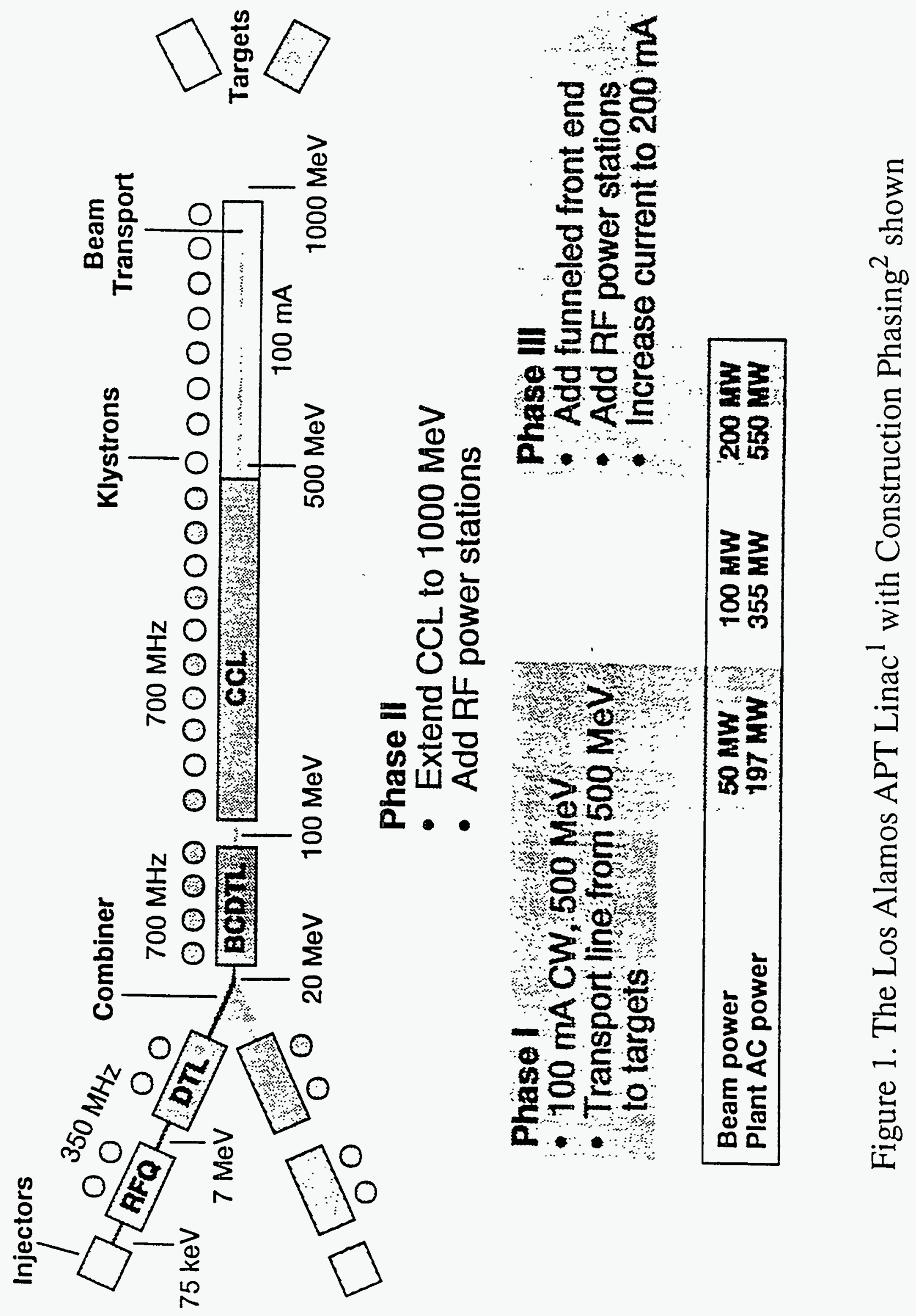




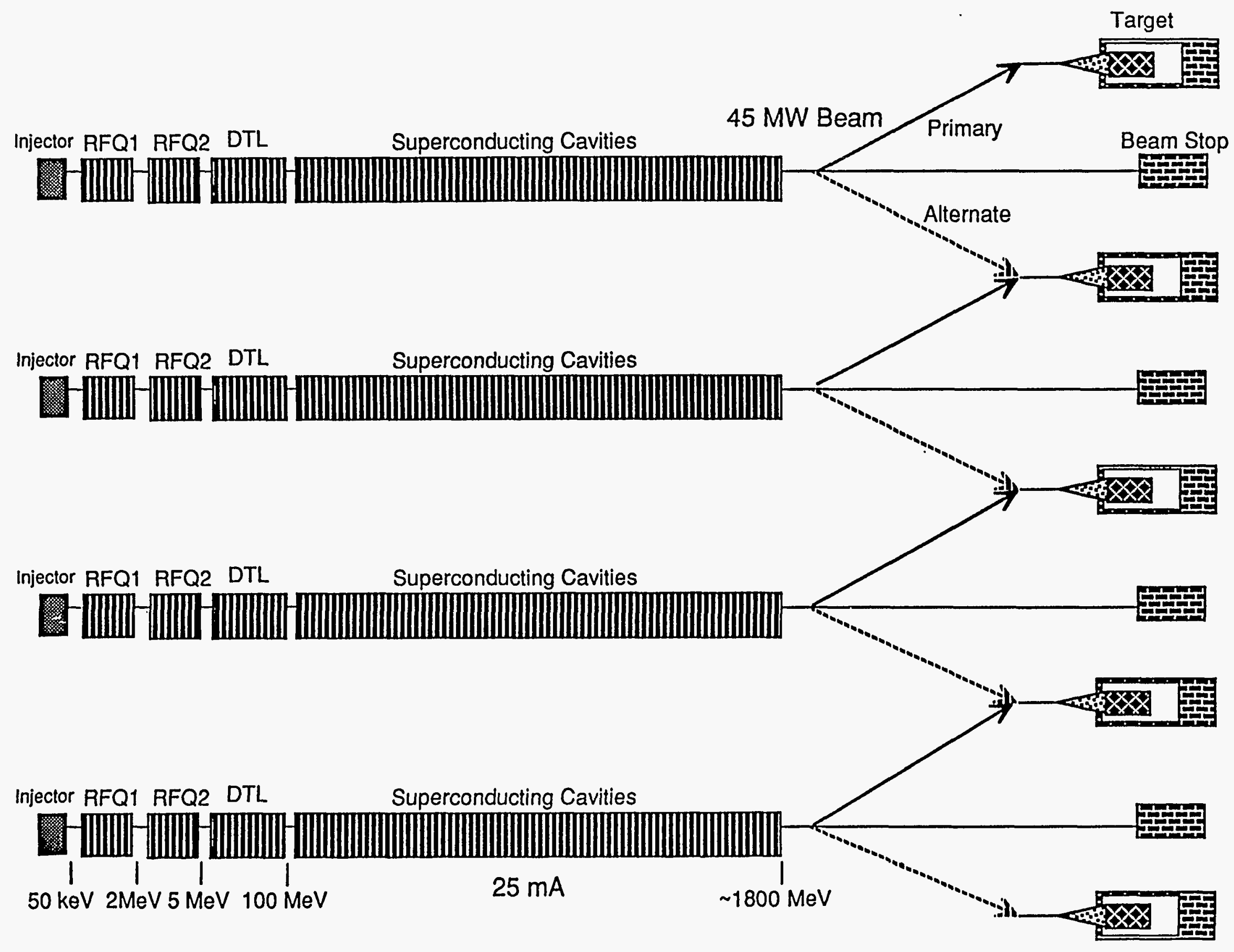

Figure 2. Multiple-Linac Approach for Tritium Production 

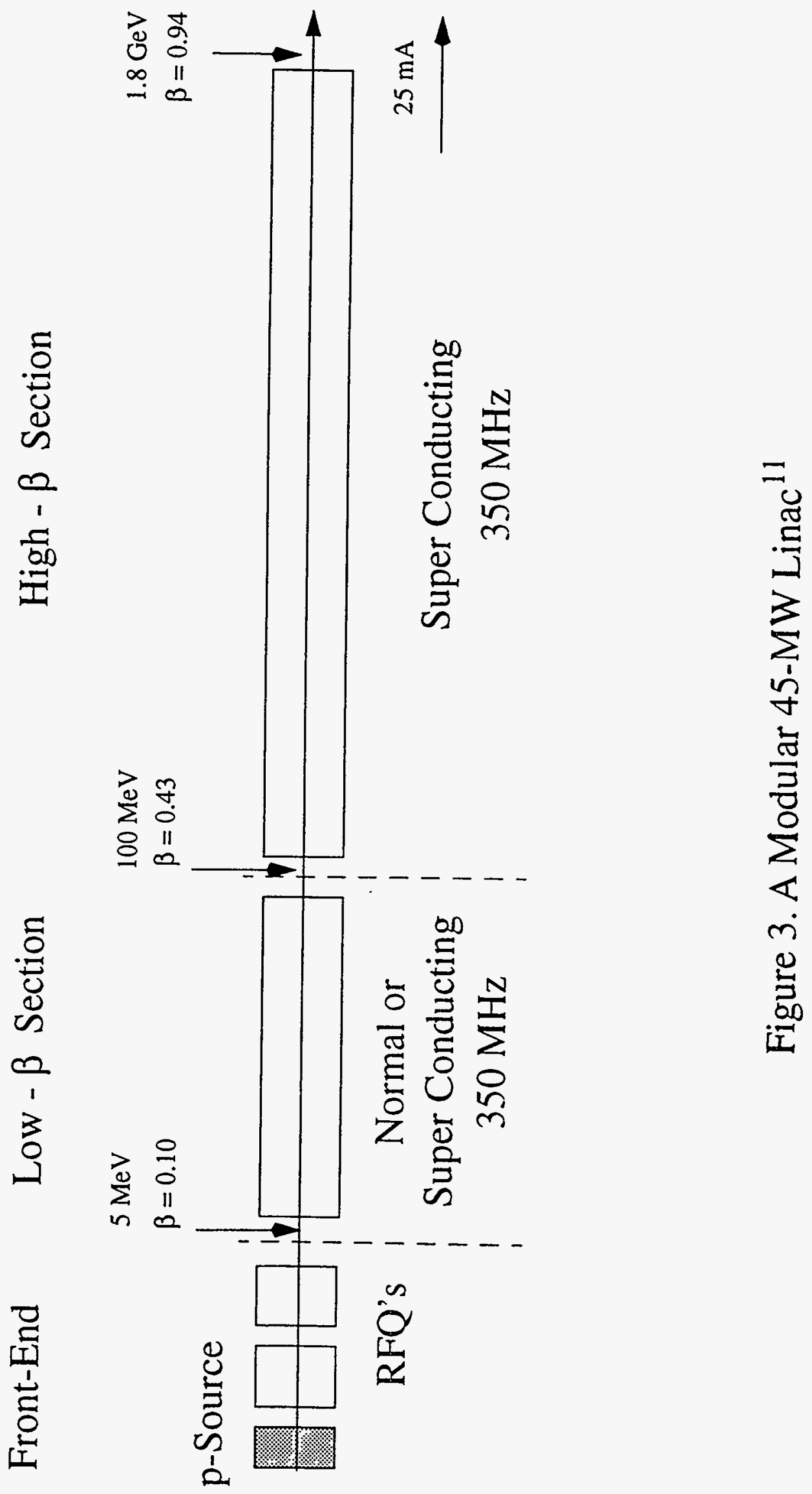


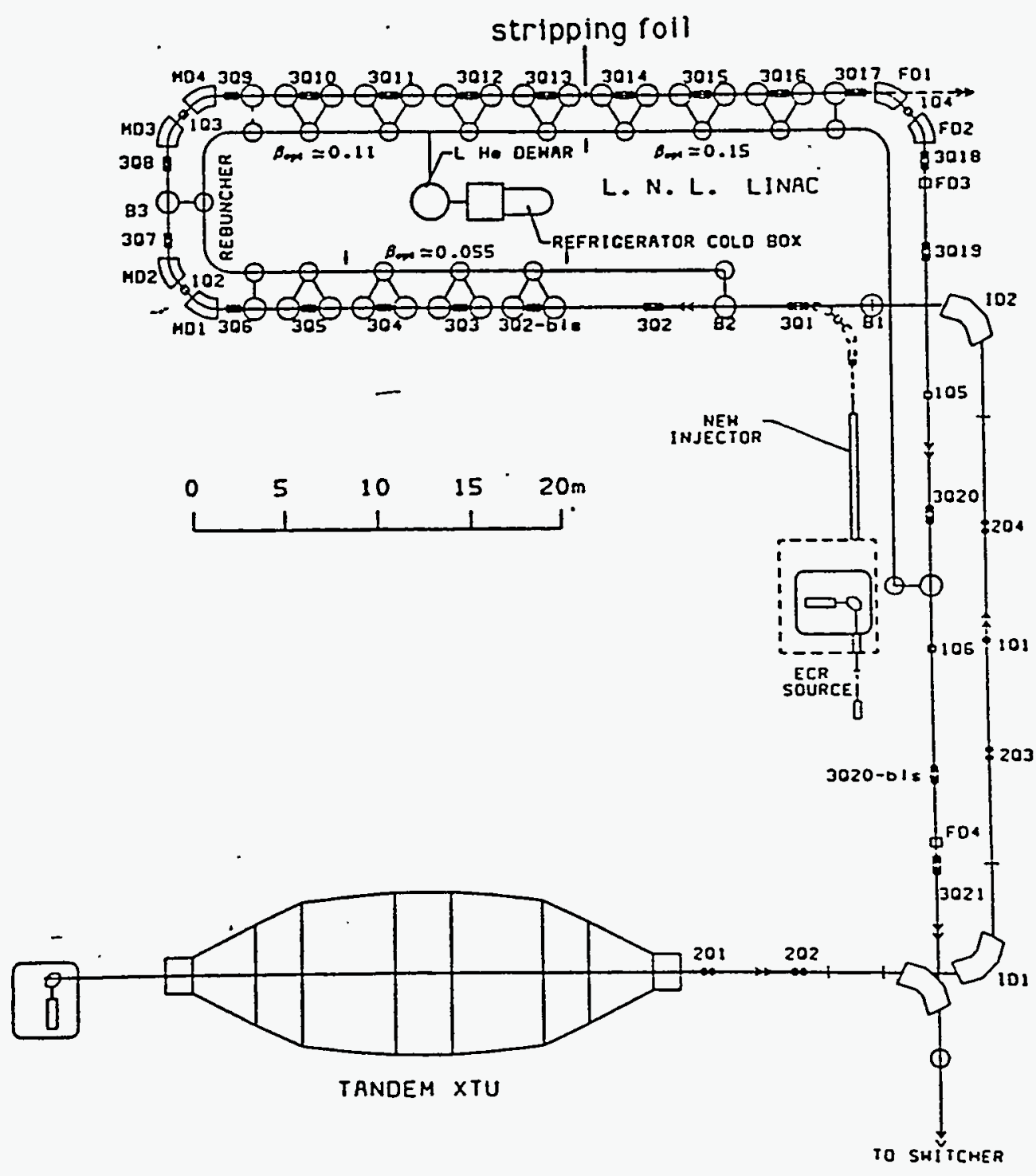

Acceleration to $5-30 \mathrm{MeV} / \mathrm{u}$ with superconducting low- $\beta$ cavities

Figure 4. The ALPI superconducting accelerator at Legnaro ${ }^{16}$ (Padua, INFN) 


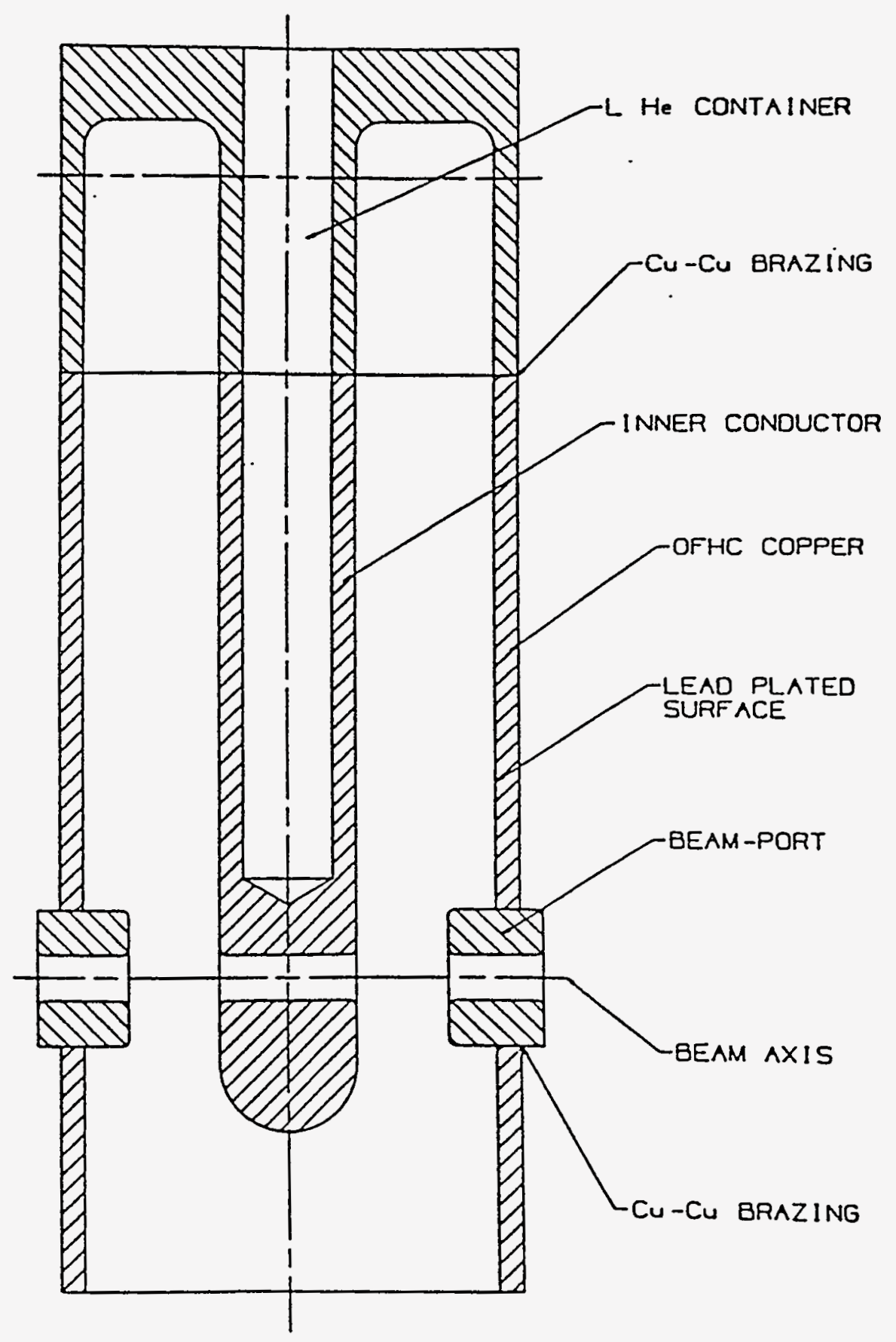

Figure 5. Quarter-Wave resonator in ALPI. ${ }^{16}$ Lead-coated Copper Cavity. 80 and $160 \mathrm{MHz}$. Gradient 2-4 MeV/m. 


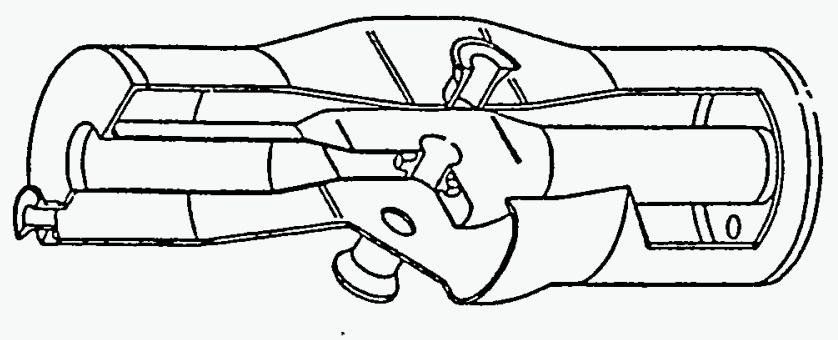

อิ

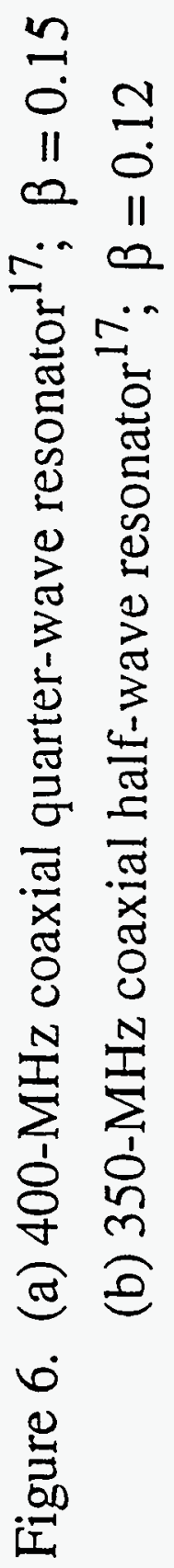



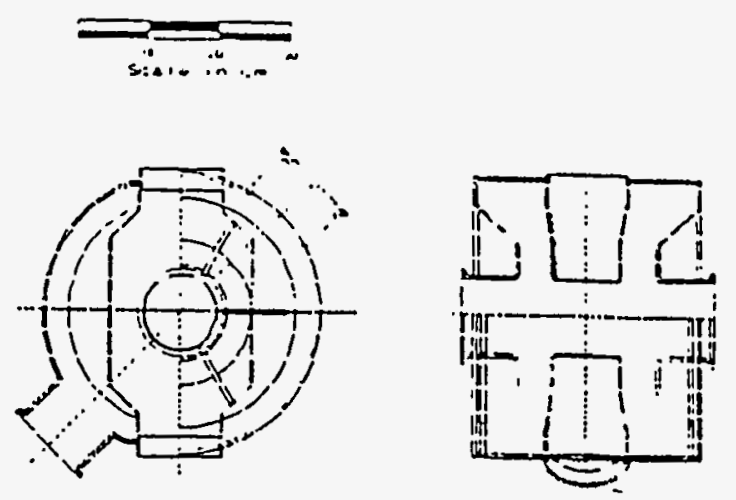

(a)

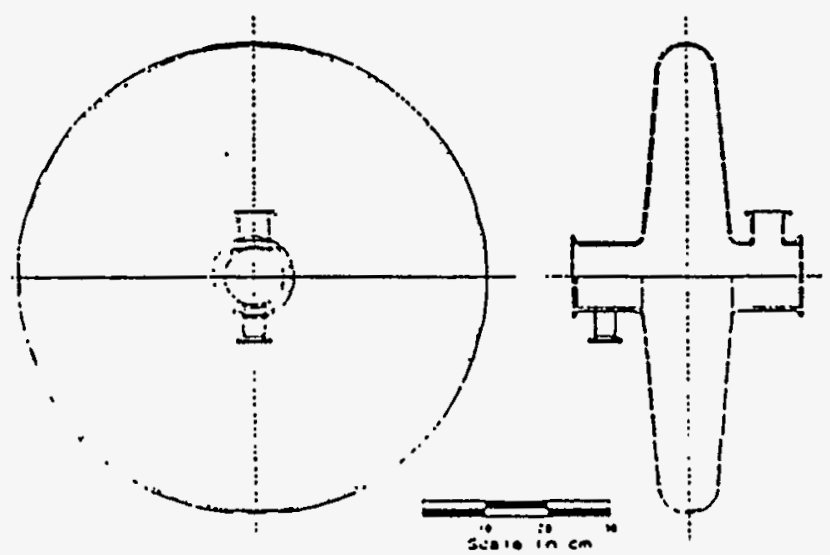

(c)
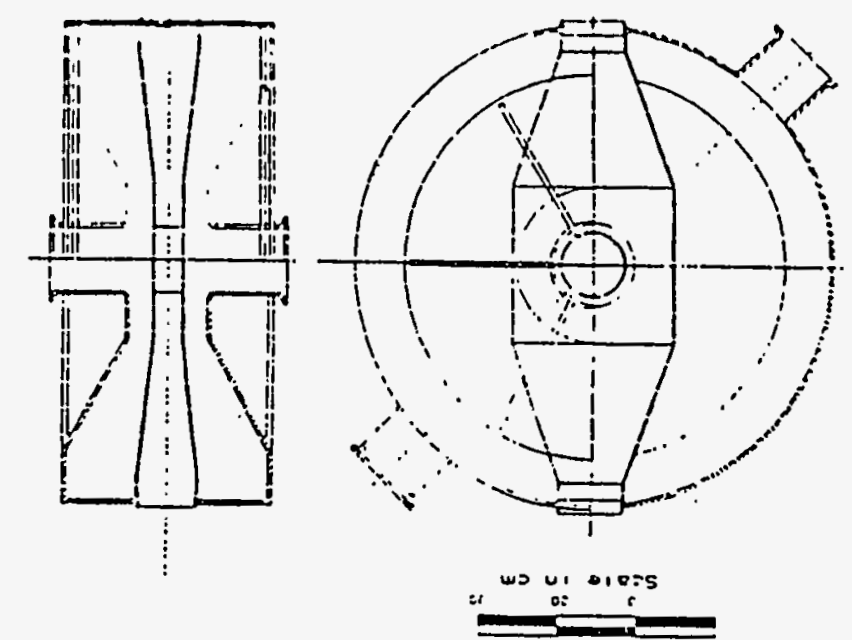

(b)

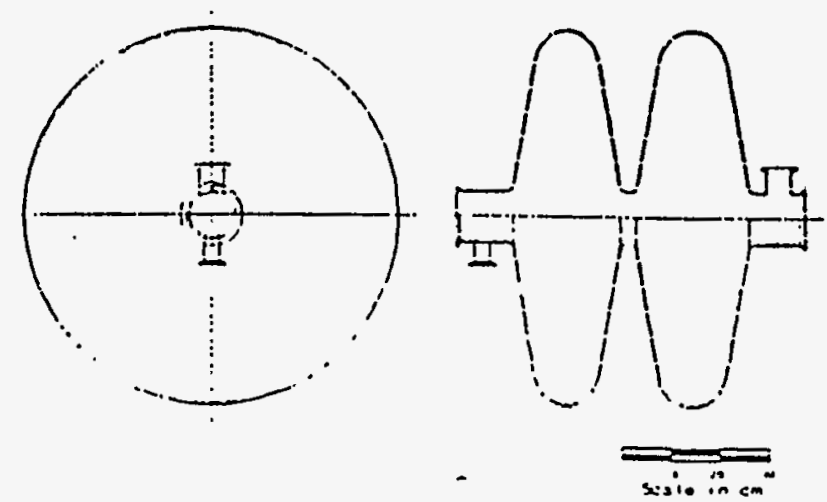

(d)

Figure 7. (a) 175-MHz 2-gap spoke resonator ${ }^{17} ; \beta=0.125$

(b) 350-MHz 2-gap spoke resonator ${ }^{17} ; \beta=0.45$

(c) $350-\mathrm{MHz}$ single-cell $\mathrm{TM}_{010}$ resonator $^{17} ; \beta=0.45$

(d) 350-MHz 2-cell $\mathrm{TM}_{010}$ resonator $^{17} ; \beta=0.8$ 

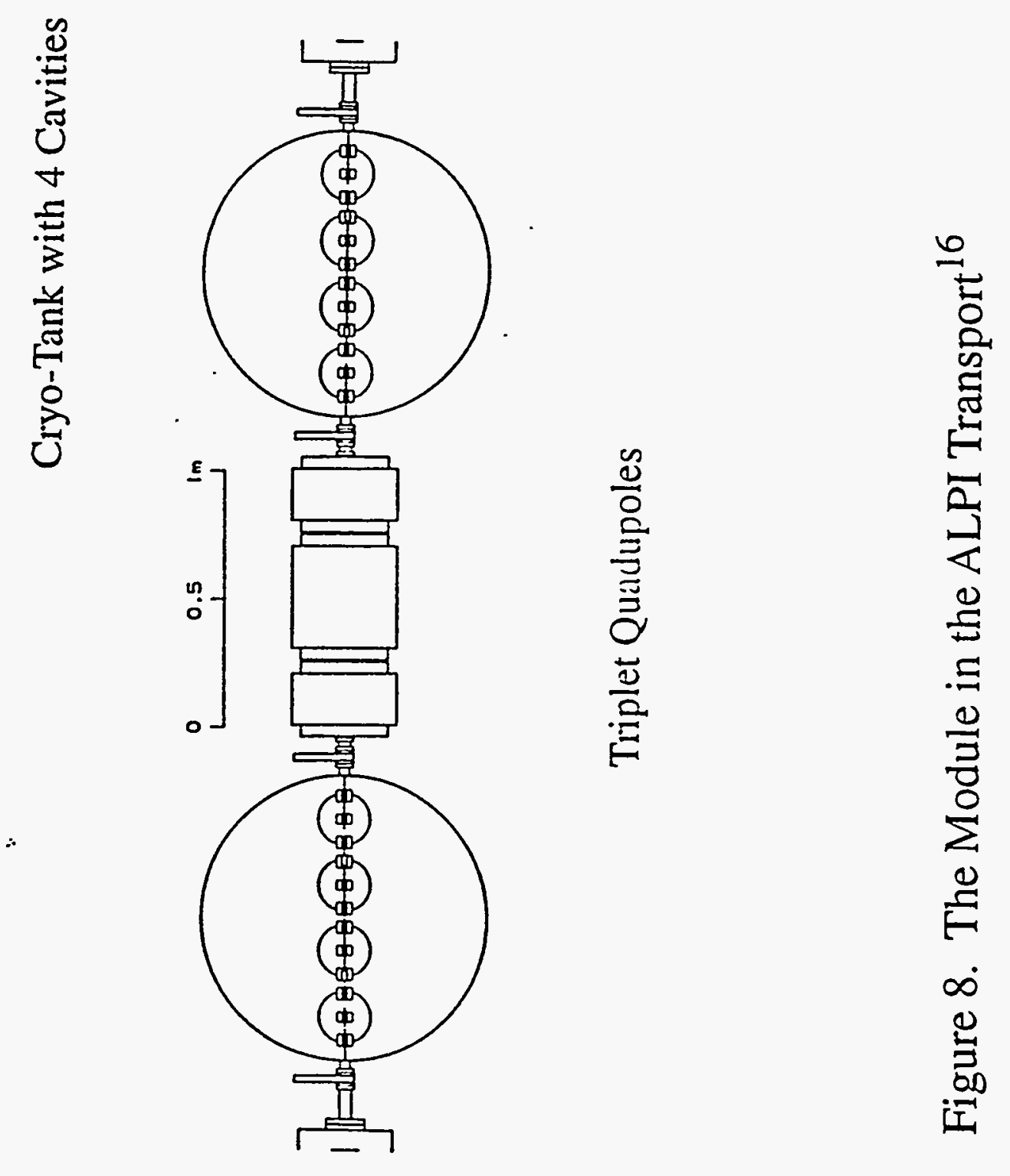

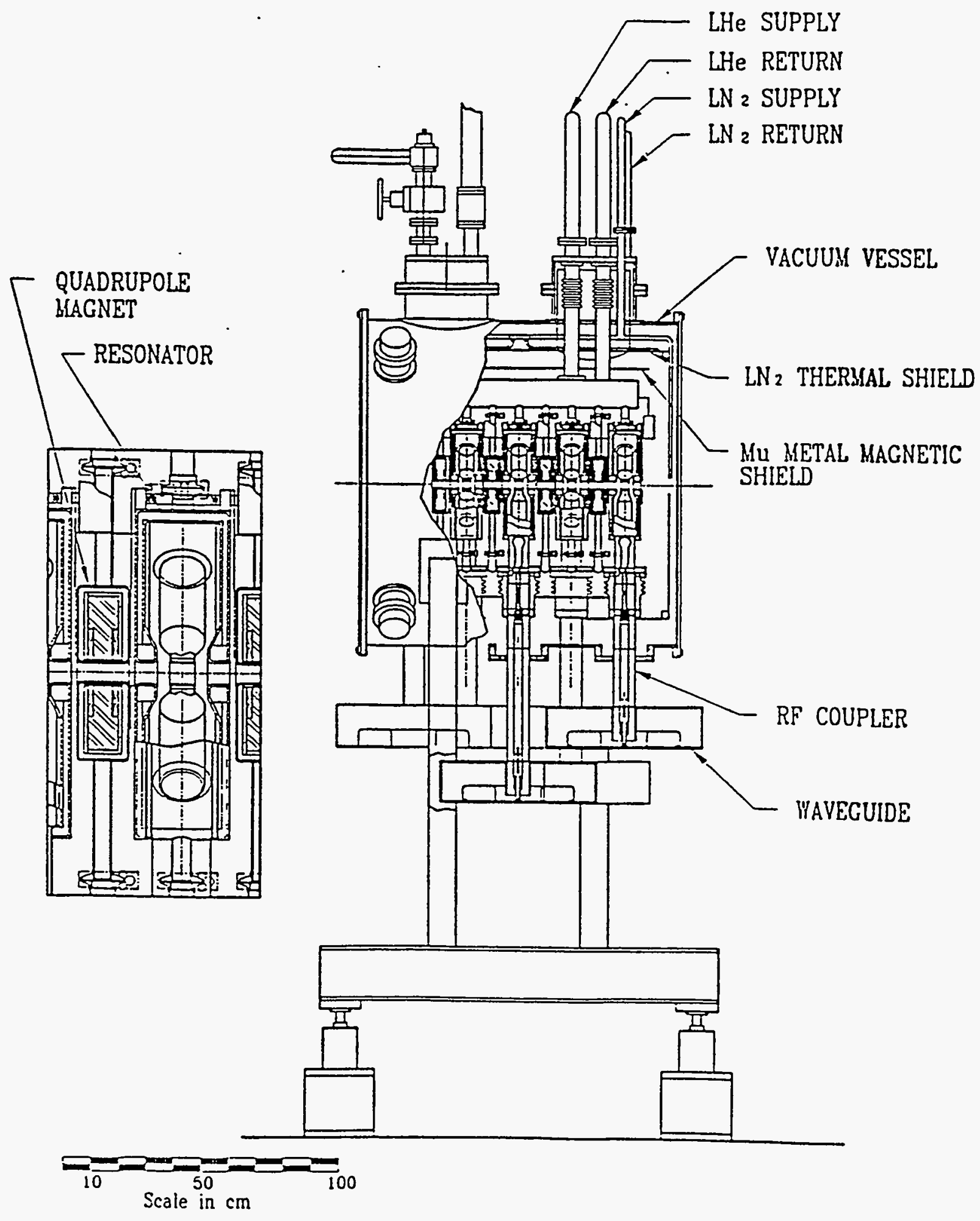

Figure 9. Conceptual drawing of a high-current superconducting linac section ${ }^{18}$. It comprises 5 accelerating cavities operating at $352 \mathrm{MHz}$.

Focusing is provided by superconducting quadrupoles located between the cavities. 


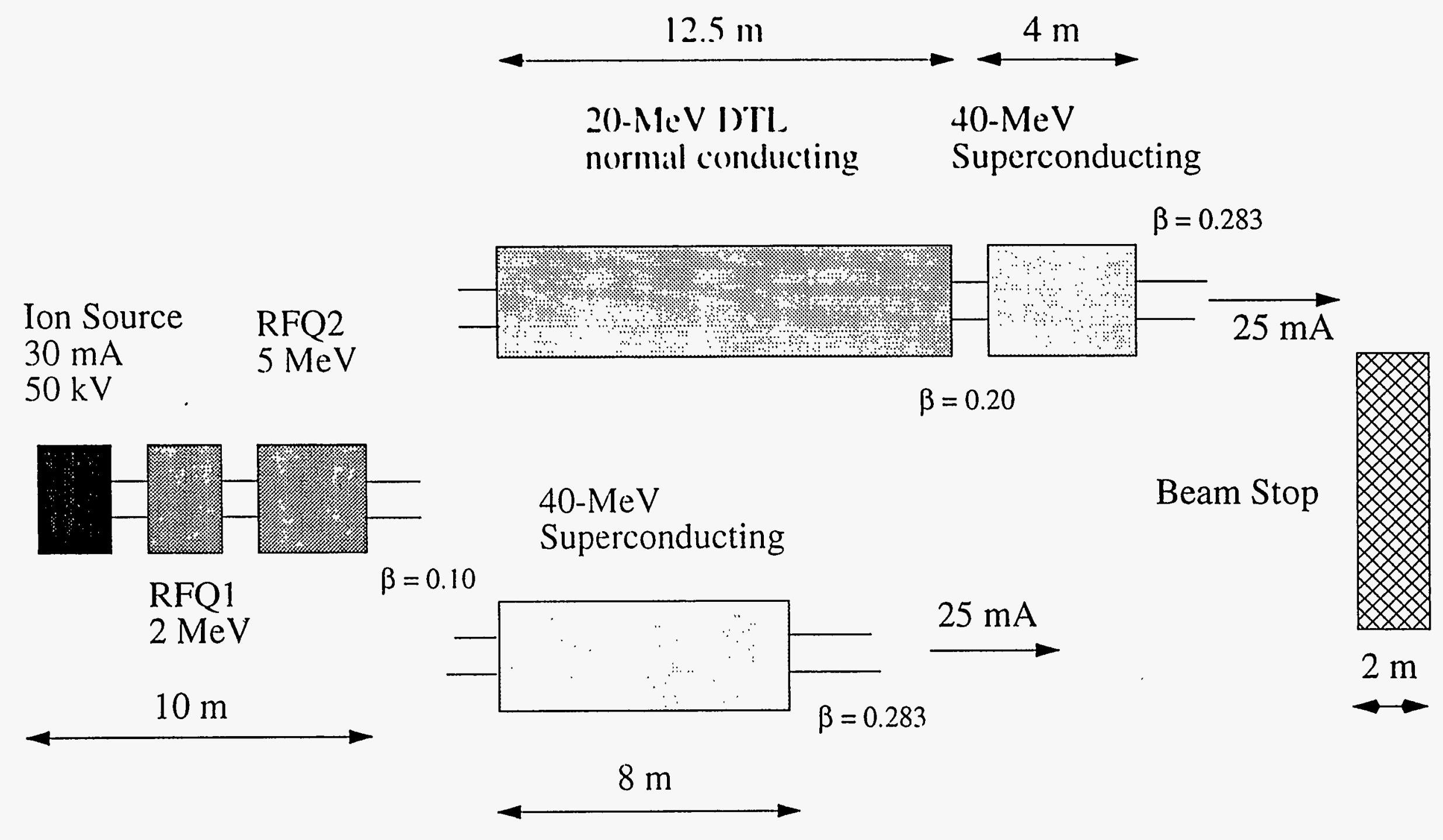

Figure 10. Experimental Set-Up to demonstrate Acceleration of Protons in Continuous Mode of Operation ${ }^{24}$ 


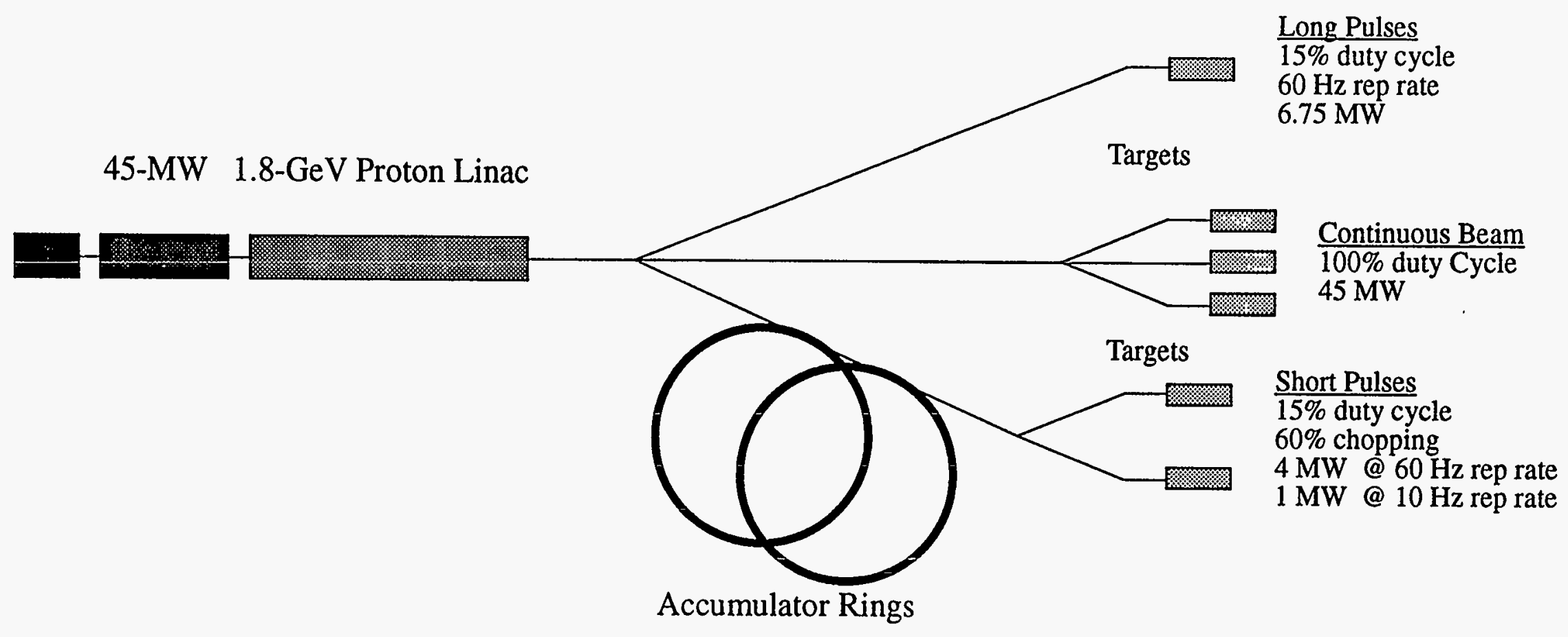

Figure 11. Layout of the Advanced Neutron Source. Neutrons are generated by spallation from a 45-MW 1.8-GeV proton Linac. Three modes of operation are possible: Continuous Beam, Long Pulses, and Short Pulses. For the latter mode the beam is compressed in one of two Accumulator Rings for 10 and 60 pulses per second. 


$\begin{array}{ll} & \text { Holding Ring } \\ \text { Linac } & 8 \mathrm{GeV} \\ 1.8 \mathrm{GeV} & \mathrm{h}=4 \\ \text { rep rate } 30 \mathrm{~Hz} & \text { d. c. } \\ \text { Beam Chopping } 60 \% & \text { ave. Beam Power } 3.0 \mathrm{MW} \\ \text { duty cycle } 2.5 \% & \text { ave. Beam Current } 380 \mu \mathrm{A} \\ \text { Peak Beam Current } 25 \mathrm{~mA} & \text { Circumference } 726 \mathrm{~m}\end{array}$

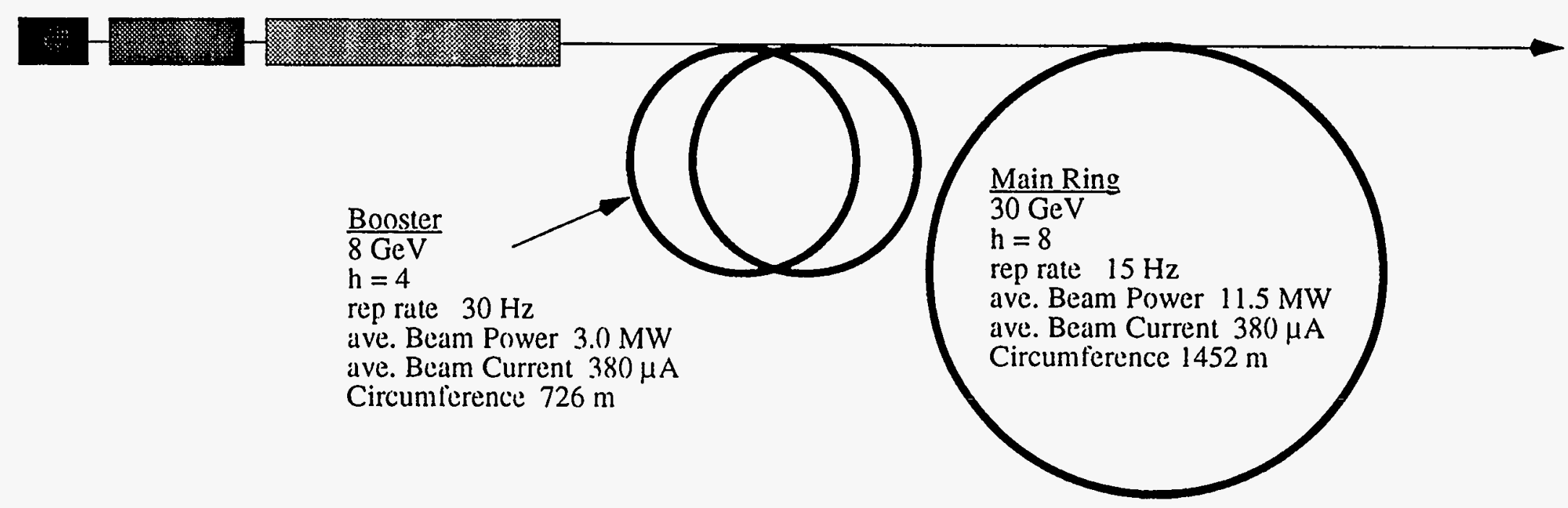

Figure 12. Layout of the Advanced Proton Source: A Facility for Nuclear and HighEnergy Physics Applications, as generation of intense Beams of Muons. 


\section{DISCLAIMER}

This report was prepared as an account of work sponsored by an agency of the United States Government. Neither the United States Government nor any agency thereof, nor any of their employees, makes any warranty, express or implied, or assumes any legal liability or responsibility for the accuracy, completeness, or usefulness of any information, apparatus, product, or process disclosed, or represents that its use would not infringe privately owned rights. Reference herein to any specific commercial product, process, or service by trade name, trademark, manufacturer, or otherwise does not necessarily constitute or imply its endorsement, recommendation, or favoring by the United States Government or any agency thereof. The views and opinions of authors expressed herein do not necessarily state or reflect those of the United States Government or any agency thereof. 